\title{
Disruption of Sertoli-Germ Cell Adhesion Function in the Seminiferous Epithelium of the Rat Testis Can be Limited to Adherens Junctions Without Affecting the Blood-Testis Barrier Integrity: An In Vivo Study Using an Androgen Suppression Model
}

\author{
WEILIANG XIA, ${ }^{1}$ CHING HANG WONG, ${ }^{1}$ NIKKI P.Y. LEE, ${ }^{1}$ WILL M. LEE, ${ }^{2}$ AND C. YAN CHENG ${ }^{1}$ * \\ ${ }^{1}$ Population Council, York Avenue, New York, New York \\ ${ }^{2}$ Department of Zoology, University of Hong Kong, Hong Kong, China
}

\begin{abstract}
During spermatogenesis, both adherens junctions (AJ) (such as ectoplasmic specialization (ES), a testis-specific AJ type at the Sertoli cell-spermatid interface (apical ES) or Sertoli-Sertoli cell interface (basal ES) in the apical compartment and BTB, respectively) and tight junctions (TJ) undergo extensive restructuring to permit germ cells to move across the blood-testis barrier (BTB) as well as the seminiferous epithelium from the basal compartment to the luminal edge to permit fully developed spermatids (spermatozoa) to be sloughed at spermiation. However, the integrity of the BTB cannot be compromised throughout spermatogenesis so that postmeiotic germ cell-specific antigens can be sequestered from the systemic circulation at all times. We thus hypothesize that AJ disruption, unlike other epithelia, can occur without compromising the BTB-barrier, even though these junctions, namely TJ and basal ES, coexist side-by-side in the BTB. Using an intratesticularly androgen suppression-induced germ cell loss model, we have shown that the disruption of AJs indeed was limited to the Sertoli-germ cell interface without perturbing the BTB. The testis apparently is using a unique physiological mechanism to induce the production of both TJ- and AJ-integral membrane proteins and their associated adaptors to maintain BTB integrity yet permitting a transient loss of cell adhesion function by dissociating $\mathrm{N}$-cadherin from $\beta$-catenin at the apical and basal ES. The enhanced production of TJ proteins, such as occludin and ZO-1, at the BTB site can supersede the transient loss of cadherin-catenin function at the basal ES. This thus allows germ cell depletion from the epithelium without compromising BTB integrity. It is plausible that the testis is using this novel mechanism to facilitate the movement of preleptotene and leptotene spermatocytes across the BTB at late stage VIII through early stage IX of the epithelial cycle in the rat while maintaining the BTB immunological barrier function. J. Cell. Physiol. 9999: 1-17, 2005. @ 2005 Wiley-Liss, Inc.
\end{abstract}

Cell junctions are ubiquitous structures in multicellular organisms serving an array of biological functions. These include adhering cells to form specialized epithelia, sensing the environment, and providing the means for cell-cell communications (for ${ }^{\mathrm{Q} 2}$ reviews, see Alberts et al., 2002; Braga, 2002; Perez-Moreno et al., 2003; Mruk and Cheng, 2004a). In virtually all the epithelia found in mammals including the skin, collecting tubules in the kidney, the respiratory tract, and the intestine, tight junctions (TJ) are located at the apex of a cell epithelium, furthest away from the basal lamina, to be followed by cell-cell actin-based adherens junctions (AJs) that form the adhesion belt, underneath of which lies the cell-cell intermediate filament-based desmosomes, these structures are referred to as the junctional complex (for reviews, see Alberts et al., 2002; Braga, 2002; Perez-Moreno et al., 2003; Lee and Cheng, 2004b; Mruk and Cheng, 2004a,b). Because of this intimate relationship between these junctions, a disruption of AJs can impair the TJ-barrier function and vice versa in many epithelia, such as those found in keratinocytes, which is a generally accepted cell physiological phenomenon (Troxell et al., 1999; Man et al., 2000; Gassler et al., 2001; Venkiteswaran et al., 2002; Guo et al., 2003). Interestingly, in the seminiferous epithelium of mammalian testes, such as rats, TJ, AJ, and desmosomes are not distinctly separated from one another to form the junctional complex, instead TJ co-exists side-by-side with two testis-specific AJ types called basal ectoplasmic specialization (ES) and basal tubulobulbar complex (TBC), forming the blood-testis barrier (BTB), which lies adjacent to the basement membrane, a modified form of extracellular matrix; whereas other AJs, such as apical ES, are found between round/elongating/elongate spermatids and Sertoli cells in the seminiferous epithelium (for reviews, see Russell and Peterson, 1985; Dym, 1994; Vogl et al., 2000; Toyama et al., 2003; Mruk and Cheng, 2004b; Siu and Cheng, 2004a,b). Unlike other TJ-barriers such as the blood-brain, the blood-epididymal, and the blood-retinal barriers, BTB must physically open to facilitate the migration of developing preleptotene and leptotene spermatocytes, which are in micrometers in diameter, at late stage VIII through early stage IX of the epithelial cycle (Russell, 1977) while maintaining the BTB integrity so that postmeiotic germ cell antigens can be sequestered from the systemic circulation. Furthermore, extensive AJ restructuring between Sertoli and germ cells occur during spermatogenesis to facilitate the timely migration of developing germ cells across the seminiferous epithelium in the rat

Contract grant sponsor: National Institutes of Health (NICHD); Contract grant numbers: U01 HD045908, U54 HD029990; Contract grant sponsor: CONRAD Program (CICCR); Contract grant number: CIG 01-72.

*Correspondence to: C. Yan Cheng, Population Council, 1230 York Avenue, New York, NY 10021.

E-mail: y-cheng@popcbr.rockefeller.edu

Received 8 December 2004; Accepted 20 January 2005

Published online in Wiley InterScience

(www.interscience.wiley.com.), 00 Month 2005.

DOI: $10.1002 /$ jcp. 20377 
testis without compromising the BTB integrity. As such, the testis must have a mechanism in place that regulates the TJ-barrier integrity at the BTB while permitting AJ restructuring. We hypothesize that Sertoli-germ cell AJ disruption in the seminiferous epithelium, unlike other epithelia, does not lead to a disruption of the TJ-barrier function. To test this hypothesis and to address this intriguing cellular physiology phenomenon pertinent to spermatogenesis regarding the functional interrelationship between TJ and AJ in the seminiferous epithelium, we have used an androgen suppression-induced Sertoli-germ cell AJ restructuring model.

Testosterone is one of the most important regulators of spermatogenesis and it is also one of the prime targets for hormonal male contraception (for reviews, see McLachlan et al., 2002b; Kamischke and Nieschlag, 2004). In previous studies, an increase in endogenous testosterone in the systemic circulation using testosterone and estrogen implants in adult rats can lead to a suppression of intratesticular testosterone, inducing depletion of spermatids (from step 9 and beyond) from the seminiferous epithelium (McLachlan et al., 1994; O'Donnell et al., 1996). Although the detailed mechanism of this spermatid sloughing is still unclear, it was shown to involve Sertoli-germ cell AJ disruption, in particular, at the apical ES (O'Donnell et al., 2000; McLachlan et al., 2002a,b). As such, this model was used to assess if a disruption of AJs that led to spermatid loss would compromise the BTB integrity. Recent studies have identified three putative ES-associated protein complexes in the rat testis crucial to ES dynamics, including the cadherin/catenin, the nectin/afadin, and the integrin/laminin protein complexes (for a review, see Lee and Cheng, 2004b). We therefore sought to investigate the loss of spermatids from the epithelium during intratesticular androgen suppression, is mediated via changes in protein-protein interaction in the ES protein complex. These are the subjects of this report.

\section{MATERIALS AND METHODS Animals}

Male Sprague-Dawley rats weighing between 250 and $280 \mathrm{~g}$ were purchased from Charles River Laboratories (Kingston, MA). The use of animals for studies reported herein was approved by the Rockefeller University Animal Care and Use Committee, with Protocol Numbers 00111 and 03017.

\section{Preparation of steroid implants}

Androgen and estrogen implants were prepared by filling testosterone (Cat. \#T-1500) or estradiol-17 $\beta$ (Cat. \#E-8875) (Sigma, St. Louis, MO) to ethylene and vinyl acetate (EVA) tubing (Elvax $770,9 \%$ VA; $2.15 \mathrm{~mm}$ ID $\times 2.4 \mathrm{~mm}$ OD, DuPont $^{\mathrm{Q} 3}$ ). Earlier studies have estimated that implants using EVA had a steroid (e.g., MENT, $7 \alpha$-methyl-19-nortestosterone) release rate of $90 \mu \mathrm{g} / \mathrm{cm} /$ day in vivo (in humans) when placed under the skin (Noe et al., 1999; von Eckardstein et al., 2003) versus $\sim 30 \mu \mathrm{g} / \mathrm{cm} /$ day for Silastic implants (Kincl et al., 1968; Robaire et al., 1979). Both ends of the EVA tubing were sealed by heat. Timplants were either 3 or $4 \mathrm{~cm}$ in length; $E$ implants were $0.4 \mathrm{~cm}$ in length. Empty implants, $4 \mathrm{~cm}$, without any steroid, were also prepared that served as vehicle controls.

\section{Experimental design}

Rats were randomly assigned to three groups with three rats for each time point in each group as follows. Group I: rats received one $3-\mathrm{cm} \mathrm{T}$ and one $0.4-\mathrm{cm} \mathrm{E}$ implants on day 0 ; Group II: TE implants were administered in rats on day 0 and removed on day 28 , and rats were allowed to recover spontaneously (i.e., natural recovery); Group III: TE implants were administered on day 0 and removed on day 28 , and four 4-cm T implants were inserted to the same site to permit rapid recovery. All implants were inserted subdermally to the dorsal side of adult rats. About three rats per time point in Group I were terminated on day 4, 8, 12,20, and 28; in Group II, rats were terminated on day 29, 35, 42,49, and in Group III, on day $29,30,42,49$. Controls included rats without any implants but terminated on day $0,12,28,42$, and rats received TE implants, but replaced with $4 \times 4 \mathrm{~cm}$ empty implants on day 28 , and terminated on day 29 and 35 thereafter.

\section{Animal surgery}

Animal surgery was performed with rats under anesthesia using Ketamine $\mathrm{HCl}$ (Ketaset, Fort Dodge Animal Health, Fort Dodge, IA) at $75 \mathrm{mg} / \mathrm{kg}$ b.w. administered via i.m. Hair at the surgical area were removed, and cleansed by scrubbing $70 \%$ alcohol and Betadine ( $2 \times$ each). A small insertion site of $\sim 2.5 \mathrm{~cm}$ was opened, and implants were carefully inserted subcutaneously. Prior to their use, implants were briefly cleansed by immersing into $70 \%$ alcohol for decontamination. For TE treatment, one $3-\mathrm{cm} \mathrm{T}$ implant and one $0.4-\mathrm{cm} \mathrm{E}$ implant were embedded; and for recovery under high $\mathrm{T}$ condition, $4 \times 4 \mathrm{~cm}$ T implants were embedded under the same site after TE implants were removed on day 28. For rats that underwent spontaneous natural recovery (SR), no implants were used after TE implants removal. Surgical site was stitched and was removed on day 7 after operation.

\section{Preparation of samples}

Rats were terminated at specific time points by $\mathrm{CO}_{2}$ asphyxiation and body weights were recorded. Testes with epididymides attached were removed and photographed. Testes were weighed and snap frozen in liquid nitrogen, and stored at $-80^{\circ} \mathrm{C}$ until use.

\section{Lysates preparation and immunoblottings}

Lysates were prepared essentially as earlier described using a lysis buffer (10 mM Tris, $0.15 \mathrm{M} \mathrm{NaCl}, 2 \mathrm{mM}$ PMSF, $2 \mathrm{mM}$ EDTA, $2 \mathrm{mM} N$-ethylmaleimide, $1 \% \mathrm{NP}-40$ [vol/vol], $1 \mathrm{mM}$ sodium orthovanadate, $0.1 \mu \mathrm{M}$ sodium okadate, and $10 \%$ glycerol [vol/vol]) (Lee et al., 2003; Lui et al., 2003c; Siu et al., 2003b) and protein estimation was carried out using the Coomassie blue dye-binding assay (Bradford ${ }^{\mathrm{Q} 4}$, 1976) with BSA as a standard. For subsequent co-immunoprecipitation (Co-IP) experiments, lysates were prepared in the same lysis buffer. Antibodies and the sources of antibodies used in this study were summarized in Table 1 . Immunoblottings were carried out using $\sim 150 \mu \mathrm{g}$ protein from each sample for SDSPAGE as previously described (Lee et al., 2003; Lui et al., 2003c; Siu et al., 2003b; Wong et al., 2004) using 7.5\%-12.5\% T SDS polyacrylamide gels (Laemmli, 1970). All samples within an experimental group were processed simultaneously to eliminate interexperimental variations.

\section{Immunohistochemistry}

Immunohistochemistry was performed essentially as previously described (Siu et al., 2003b). Frozen testes were embedded in OCT compound (Sakura Finetek USA, Inc., Torrance, CA) and sectioned at $7 \mu \mathrm{m}$ in thickness using a microtome in a cryostat (Hacker, Fairfield, NJ) at $-20^{\circ} \mathrm{C}$, mounted onto poly-L-lysine coated slides and stained for JAM-1 with a Histostain-SP ${ }^{\mathrm{TM}}$ kit (Zymed Laboratories, South San Francisco, CA). Sections were counterstained by hematoxylin as described (Siu et al., 2003b; Siu and Cheng, 2004c). Sections were examined under an Olympus BX-40 microscope (Olympus Corp., Melville, NY) and photographed using an Olympus DP70 12.5 MPa Digital Camera. All images were acquired using the QImaging QCapture Suite (Version 2.6) Software Package from Quantitative Imaging Corp. (Burnaby, BC, Canada) and analyzed with Adobe PhotoShop (Version 7.0). Controls included the use of normal rabbit serum, rabbit IgG, or PBS to substitute the primary antibody.

\section{Immunofluorescent microscopy}

Fluorescent microscopy was performed essentially as previously described (Lee et al., 2003, 2004; Siu et al., 2003b; Siu and Cheng, 2004c). Fluorescein isothiocyanate (FITC)- and 
TABLE 1. Summary of primary antibodies used for different immunological experiments

\begin{tabular}{|c|c|c|c|c|c|c|}
\hline Vendor & $\begin{array}{c}\text { Antibody against } \\
\text { target protein }\end{array}$ & Animal source & Catalog \# & Lot \# & Usage & $\begin{array}{l}\text { Working } \\
\text { dilution }\end{array}$ \\
\hline \multirow{9}{*}{$\begin{array}{l}\text { Santa Cruz Biotechnologies } \\
\text { (Santa Cruz, CA) }\end{array}$} & Actin & Goat $^{\mathrm{a}}$ & sc-1616 & D052 & IB & $1: 1,000$ \\
\hline & Claudin-11 & Goat & sc- 13641 & A162 & IB & $1: 200$ \\
\hline & N-cadherin & Rabbit & sc-7939 & J1502 & IB & $1: 200$ \\
\hline & E-cadherin & Rabbit & sc-7870 & C212 & IB & $\begin{array}{l}1.40 \\
1: 200\end{array}$ \\
\hline & $\alpha$-catenin & Rabbit & sc-7894 & G3003 & IB & $1: 200$ \\
\hline & $\beta$-catenin & Rabbit & sc-7199 & L0203 & IB & $1: 200$ \\
\hline & & & & & IP & $1: 40$ \\
\hline & Nectin-3 & Goat & sc-14806 & $\mathrm{K} 261$ & IB & $1: 100$ \\
\hline & Laminin $-\gamma 3$ & Goat & sc-16601 & G032 & IB & $1: 200$ \\
\hline \multirow{9}{*}{$\begin{array}{l}\text { Zymed Laboratories, Inc. } \\
\text { (South San Francisco, CA) }\end{array}$} & Occludin & Rabbit & $71-1500$ & 30979485 & IB & $1: 200$ \\
\hline & JAM-1 & Rabbit & $36-1700$ & 30979650 & $\begin{array}{l}1 \mathrm{~F} \\
\mathrm{IB}\end{array}$ & $\begin{array}{l}1: 100 \\
1: 250\end{array}$ \\
\hline & & & & & IHC & $1: 100$ \\
\hline & & & & & IF & $1: 250$ \\
\hline & $\mathrm{ZO}-1$ & Rabbit & $61-7300$ & 30175033 & IB & $1: 250$ \\
\hline & ZO-1-FITC & Mouse, monoclonal & $33-9111$ & 30879018 & IF & $1: 100$ \\
\hline & $\mathrm{N}$-cadherin & Mouse, monoclonal & $33-3900$ & 30778768 & IF & $1: 100$ \\
\hline & $\beta$-catenin & Rabbit & $71-2700$ & 30477187 & IF & $1: 100$ \\
\hline & Phospho-Tyr & Mouse, monoclonal & $13-6600$ & 40186105 & IB & $1: 500$ \\
\hline Sigma-Aldrich (St. Louis, MO) & l-afadin & Rabbit & A0349 & $012 \mathrm{~K} 4875$ & IB & $1: 1,000$ \\
\hline $\begin{array}{l}\text { BD Transduction Laboratories } \\
\text { (San Diego, CA) }\end{array}$ & Integrin- $\beta 1$ & Mouse, monoclonal & 610468 & 8 & IB & $1: 500$ \\
\hline
\end{tabular}

IB, immunoblotting; IHC, immunohistochemistry; IF, immunofluorescent microscopy.

${ }^{a}$ All primary antibodies used in this study were polyclonal antibodies except otherwise specified.

Cy3-labeled goat anti-rabbit IgG were used to co-localize Ncadherin and $\beta$-catenin in the seminiferous epithelium of rat testes. A FITC-conjugated ZO-1 antibody and a Cy3-labeled goat anti-rabbit IgG were used to co-localize JAM-1 (or occludin) with ZO-1 to assess the integrity of the BTB during androgen suppression-induced germ cell loss from the epithelium as described (Wong et al., 2004). Frozen sections were obtained in a cryostat and prepared as described above. All samples from different rats within an experimental group, such as during androgen suppression-induced germ cell loss from the epithelium, were processed simultaneously with 3-4 cross-sections per slide so that all samples could be placed on 2-3 slides. This step is essential to eliminate interexperimental variations in particular differences in antibody incubation time, staining conditions and subsequent color development. Sections were treated with $10 \%$ normal goat serum (Zymed, Cat. \#01-6201, diluted in PBS) and incubated with the corresponding primary antibody pair at room temperature overnight. Sections were then washed in PBS to be followed by incubation with fluorescein-labeled secondary antibody pair. Sections were subsequently mounted in Vectashield with DAPI [4', 6-diamidino-2-phenylindole, dihydrochloride] (Vector Laboratories, Burlingame, CA), and viewed under an Olympus BX-40 microscope equipped with fluorescent optics.

\section{Image analysis}

To estimate the diffusion of proteins (e.g., $\mathrm{N}$-cadherin and $\beta$ catenin) from the site of its localization in the testis during androgen suppression-induced germ cell loss from the epithelium, assessing changes in protein-protein association besides $\mathrm{Co}$-IP, fluorescent images of $\mathrm{N}$-cadherin and $\beta$-catenin from fluorescence microscopy were acquired and photographed at the same magnification and parameters. At least 50 tubules from testes of two different rats were randomly selected and examined as follows. First, fluorescent images were photographed and printed using an Epson 890 Inject printer at $1,440 \times 720$ dpi resolution on Epson Photo papers. Second, the diffusion of a target protein staining, such as N-cadherin, from its arbitrary site of origin is defined as the distance (in $\mathrm{mm}$ ) from the BTB site near the basement membrane to the edge of visible staining away from the BTB in a treatment group, or control testes. Thus, the relative diffusion (RD) of a target protein during treatment = distance of the target protein diffused away from BTB at specified time point/the distance in control testis (mean) at the same time point. The magnification (or the absolute distance) used in our measurement did not interfere RD results because they were being canceled out in the numerator and denominator.

\section{Co-IP and an assessment of Tyr-phosphorylation content of $\boldsymbol{\beta}$-catenin}

About $500-1,200 \mu \mathrm{g}$ protein lysates from each sample were used for Co-IP studies to assess changes in protein-protein interactions during androgen depletion-induced germ cell loss. All samples within an experimental group were processed simultaneously to eliminate interexperimental variation. Co-IP was performed as described (Lee et al., 2003, 2004). In brief, lysates were pretreated with $1 \%$ (vol/vol) IgG for at least $1 \mathrm{~h}$ with agitation using a rotator (GlasCol, Terre Maute, IN) at $24 \mathrm{rpm}$. Thereafter $10 \mu \mathrm{l}$ Protein A/G-PLUS agarose (Santa Cruz Biotechnology, Inc., Santa Cruz, CA) was added and incubated for another hour. After a brief centrifugation $(1,000 \mathrm{~g}, 5 \mathrm{~min})$ to remove non-specifically interacting proteins in the pellet, supernatant was collected and incubated with the corresponding primary antibody of a target protein overnight with agitation at $4^{\circ} \mathrm{C}$. Thereafter, $20 \mu \mathrm{l}$ Protein $\mathrm{A} / \mathrm{G}$-PLUS agarose was added, and incubated for $2 \mathrm{~h}$ to precipitate immunocomplexes. Immunocomplexes were washed four times with Co-IP buffer by gentle resuspension and centrifugation. The resultant complexes were denatured in SDS-sample buffer and resolved by SDS-PAGE. Target proteins were visualized by the corresponding antibodies. Scaled-up Co-IP $(\sim 1,200 \mu \mathrm{g}$ protein per sample) was carried out to assess Tyrphosphorylation content of $\beta$-catenin. In short, about $1 / 3$ of the immunoprecipitated proteins in the scaled-up Co-IP using an anti- $\beta$-catenin antibody as the precipitating antibody were resolved by SDS-PAGE, electroblotted onto nitrocellulose and probed with an anti-phospho-Tyr antibody. Immunostained protein band on the blot that had the same electrophoretic mobility as of $\beta$-catenin $(\sim 92 \mathrm{kDa})$ was identified. Because $\beta$ catenin protein levels were induced during androgen suppression-induced germ cell loss, measures were taken to correct for the increasing $\beta$-catenin protein level as follows. First, the same amount of SDS sample buffer was added to each sample to extract immunocomplexes from the scale-up Co-IP experiment. Second, only $1 / 3$ of this IP product was resolved by SDSPAGE and the $\beta$-catenin protein levels were estimated by densitometric scanning of the protein blot. Third, based on this semi-quantitative scanning data, the same amount of $\beta$ catenin that was immunoprecipitated between samples within 
the treatment group was resolved on another SDS-polyacrylamide gel. Fourth, after phospho-Tyr immunostaining, this same blot was stripped and reprobed with a $\beta$-catenin antibody confirming the level of $\beta$-catenin was indeed uniform in all samples within the treatment group. As such, any changes in phospho-Tyr level in $\beta$-catenin is the result of putative changes in its phosphorylation status.

\section{Statistical analysis}

Different parameters (e.g., body and testis weights, steadystate levels of different target proteins interpolated from densitometrically scanned results after normalized against $\beta$ actin) from samples within an experimental group were compared between samples at different times versus controls and/or between pairs of samples at other time points by ANOVA using Honest Significant Test (HST) with the JMP IN software package (Version 4, SAS, Inc., Cary, NC).

\section{RESULTS}

Changes in testes weight and size, and body weight during androgen suppression-induced germ cell loss from the seminiferous epithelium

The treatment regimen that was used to induce AJ disruption, causing germ cell loss from the seminiferous epithelium by suppressing the endogenous $\mathrm{T}$ level via TE implants and the subsequent recoveries, is shown in Figure 1A. A progressive and significant loss in testes weight was detected following TE implants insertion at the time of germ cell loss (Fig. 1B, part a). By the time TE implants were removed (see solid arrow), testes weight had decreased to about half of normal testes and this trend continued for several additional days. During recovery, either spontaneously or under high $\mathrm{T}$ condition, testes weight recovered rapidly and was similar to normal rat testes within 3 weeks (Fig. 1B, part a). Such changes of testes weight were consistent with changes in testes size (Fig. 1C). For instance, testis length along the longitudinal axis decreased from $\sim 20 \mathrm{~mm}$ (control) to $\sim 15 \mathrm{~mm}$ (29D) after $\sim 4$ weeks of $\mathrm{T}$ suppression, and returned to the size virtually indistinguishable from normal testes in both recovery groups (Fig. 1C). The body weights of these rats also gained steadily from $\sim 300$ to $\sim 420 \mathrm{~g}$ in control groups when housed with access to food and water ad libitum (Fig. 1B, part b). The rate of body weight gaining was significantly smaller than controls after TE implants were placed under the skin; however, body weights were rapidly recovered in both recovery groups and the differences found between treatment groups and control rats were negligible at the end of the experimental period (Fig. 1B, part b).

\section{Did the androgen suppression induced-germ cell loss from the seminiferous epithelium disrupt the BTB integrity?}

Selected TJ-integral membrane proteins and adaptors were upregulated in androgen suppressed rat testes. Three TJ-integral membrane proteins: occludin, claudin, and JAM; and an adaptor known to exists at BTB: ZO-1, were examined. An increase in the protein levels of occludin, JAM-1 and ZO-1, but not claudin-11, was observed beginning on day 20 after TE implants (Fig. 2A,B), reaching a peak of almost three- to fivefold versus control rats on days 28-30 at the time spermatids (step 8 and beyond) were depleting from the epithelium (see below). Thereafter, the protein levels of occludin, JAM-1, and ZO-1 declined gradually when implants were removed on day 28 to permit recovery, and returned to their normal level by day 49 when the epithelium was fully recovered (Fig. 2A,B).
BTB integrity was not compromised during androgen suppression-induced germ cell loss from the epithelium. The above immunoblot data have illustrated that occludin and ZO-1 levels in the testis

\section{A Treatment schedule (time in day)}

\begin{tabular}{lllllllllll}
0 & 4 & 8 & 12 & 20 & 28 & 29 & 30 & 35 & 42 & 49 \\
\hline
\end{tabular}

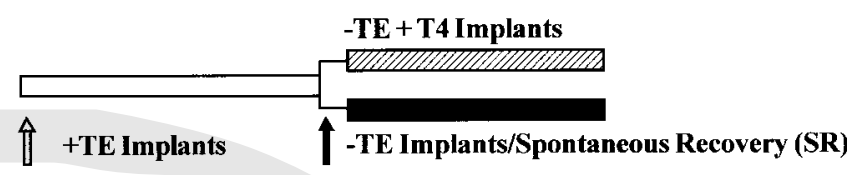

B
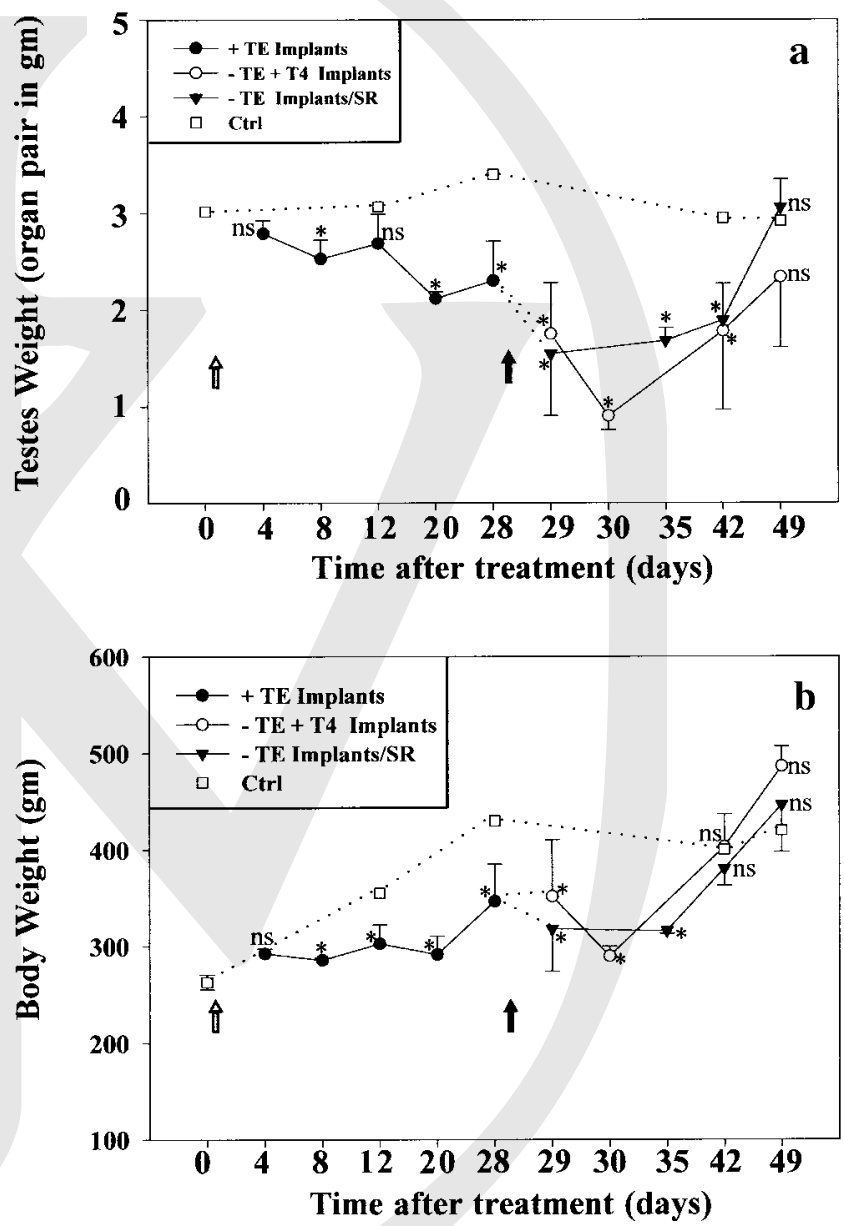

Fig. 1. A-C: A study of using TE implants to suppress intratesticular androgen levels to deplete germ cells from seminiferous epithelium and its effects on testes and body weight, and testis size in adult rats. A: The treatment regimen that was used in studies in this report. B This figure shows changes in testes weight (a) representing organ pair (g) from each animal ( $\mathrm{n}=3$ for each time point). Changes in body weight were shown in part (b). On day 0 (the date when surgery was performed), rats received TE implants. On day 28, TE implants were removed in one group of rats and replaced with $4 \times 4 \mathrm{~cm} T$ implants (T4) (-TE + T4 implants). In another group of rats, TE implants were removed and rats underwent naturally spontaneous recovery (SR) without any implants (-TE implants/SR). Open arrow indicates when TE implants were administered; closed arrow indicates when TE implants were removed to allow either androgen-induced (T4 implants) or spontaneous recovery. Each data point is the mean $\pm \mathrm{SD}$ $\mathrm{SD}$ of three rats. ns, not significantly different from control as determined by ANOVA; *, significantly different, $P<0.05 ;(\mathbf{C}, \mathbf{a}-\mathbf{g})$ shown $^{\mathrm{Q} 5}$ herein are representative photographs of testes with epididymides displaying changes in their sizes during treatment and recovery. The labeling used here is applicable to all other figures in this report. T, testosterone; $\mathrm{E}$, estrodiol-17 $\beta$ 


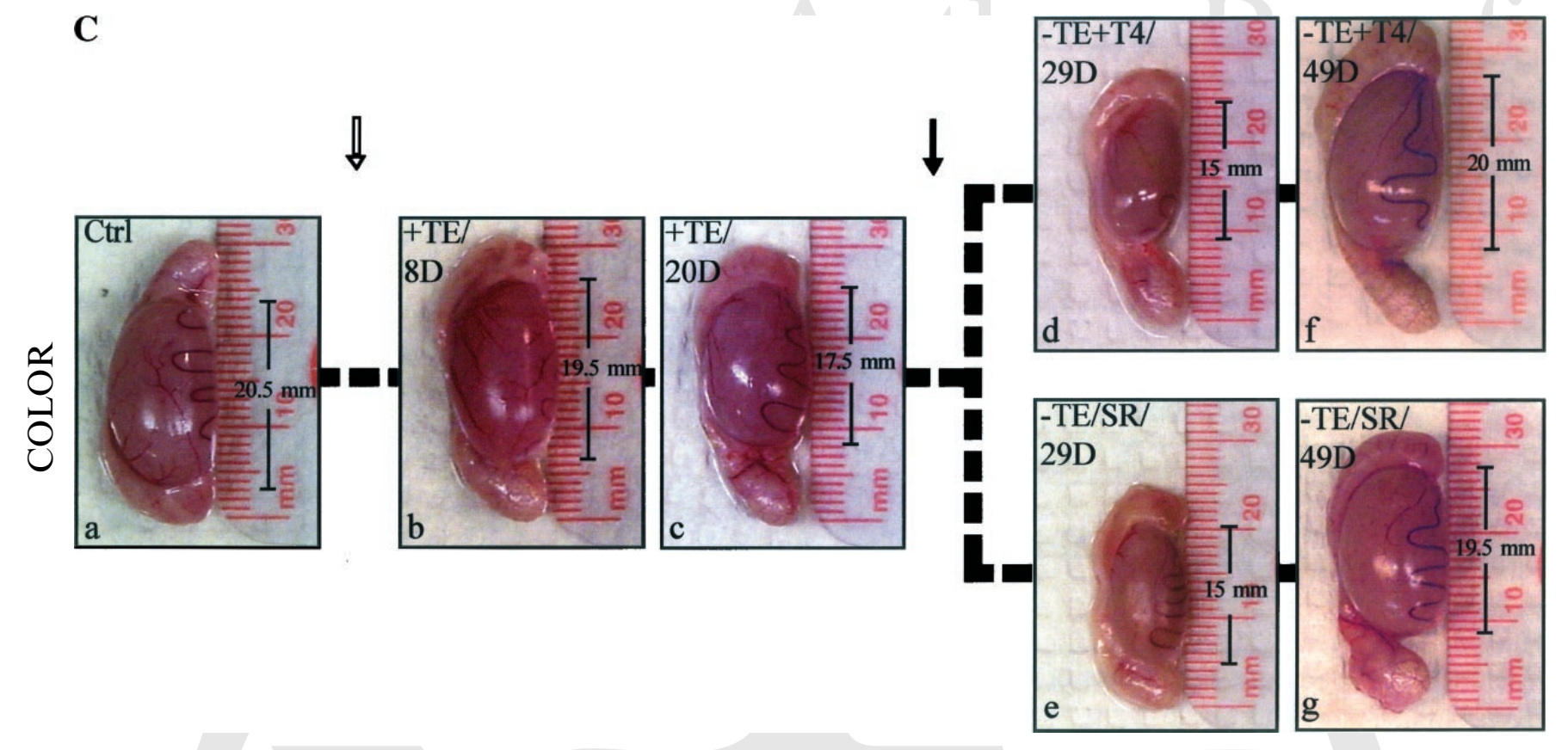

Fig. 1. (Continued)

were induced by the TE-implants mediated androgen suppression (Fig. 2A-L), yet this did not give any indication if the site of BTB had been disrupted. A recent study using fluorescence microscopy to co-localize occludin and ZO-1 to the epithelium has proven to be a novel tool to assess the BTB integrity (Wong et al., 2004), it was therefore used in this study. Both occludin and ZO-1 were localized to the same site in the basal compartment consistent with their localization at the BTB site (Fig. 3A-D), forming an almost continuous superimposable immunoreactive ring in the epithelium of a normal rat testis (Fig. 3A-C). This pattern of localization persisted in testes on day 20 (Fig. 3E-G) and 29 (Fig. 3I-K) at the time of extensive spermatids loss from the epithelium (see Fig. 4) except that there was an increase in fluorescence of occludin or ZO-1 versus control testes (Fig. $2 \mathrm{E}-\mathrm{G}, \mathrm{I}-\mathrm{K}$ vs. A-C), illustrating the BTB integrity had not been compromised, consistent with results of immunoblots that illustrate an increase in protein levels (Fig. 2).

Study using JAM-1 to further validate that BTB remained intact during androgen suppressioninduced germ cell loss from the seminiferous epithelium. To further validate the above observations, the study was extended to another TJ-integral membrane protein at the BTB namely JAM-1, since an increase in JAM-1 protein was detected during androgen suppression-induced germ cell loss (Fig. 2). Immunohistochemistry was preformed in normal rat testes in which JAM-1 appears as reddish-brown precipitates at the basal compartment of the epithelium, consistent with its localization at the BTB (Fig. 4A). JAM-1 was found to be a stage-specific protein, being highest at stages IX-XIV, but lowest at stages IV-VI. At stages IV-VI, the staining of JAM-1 at the BTB site diminished greatly (see inset I in Fig. 4A). Some JAM-1 staining was also found in the interstitium surrounding the endothelial cells of the microvessel, illustrating it is also used as a TJ-integral membrane protein in vascular TJ-barrier (Fig. 4A). Positive (Fig. 4A, part e) and negative (Fig. 4A, part d) controls were also included to assure the staining shown in Figure 4 was specific for JAM-1.
We next performed an additional immunohistochemistry experiment to examine the pattern of JAM-1 in the testis during androgen suppression-induced germ cell loss from the epithelium (Fig. 4B). Consistent with the immunoblotting data shown in Figure 2, JAM-1 staining at the basal compartment was indeed greatly induced. The insets shown in different parts in Figure $4 \mathrm{~B}$ were at lower magnification, corresponding to the selected time points of the androgen suppression regimen (See Fig. 1A). This result illustrates that amidst the progressive shrinkage of the seminiferous tubules (Fig. 4B, parts c, d vs. part a), the reddish-brown immunoreactive JAM-1 signals also gradually intensified, yet this protein continued to maintain an almost uninterruptive ring consistent with the data of occludin shown in Figure 3. This immunohistochemistry also implicated that the BTB integrity had been maintained during androgen suppression-induced germ cell loss from the epithelium (Fig. 4B).

Since JAM-1 was shown to interact with ZO-1 in other epithelia (Bazzoni et al., 2000), we sought to use fluorescence microscopy to co-localize JAM-1 and ZO-1 at the site of BTB in control testes as well as in testes by 29D after TE implants at the time of germ cell loss (see Fig. 4B). As shown in Figure 4C, parts a-d, the merged images of JAM-1 and ZO-1 was not entirely yellowish for all tubules because JAM-1 was not expressed uniformly at all stages of the epithelial cycle (Fig. 4C vs. A). Nonetheless, JAM-1 that was co-localized with ZO-1 always maintained a non-interruptive ring at the BTB site in the seminiferous epithelium during androgen suppression-induced germ cell loss (Fig. 4C-g).

\section{What is the mechanism(s) by which androgen suppression induces germ cell loss from the seminiferous epithelium?}

Changes in ES-associated protein levels during androgen suppression-induced germ cell loss from the seminiferous epithelium. Three ES-structural protein complexes have been identified in the apical ES of rat testes (for reviews, see Cheng and Mruk, 2002; Toyama et al., 2003; Lee and Cheng, 2004a,b; Mruk and 
$\mathbf{A}$
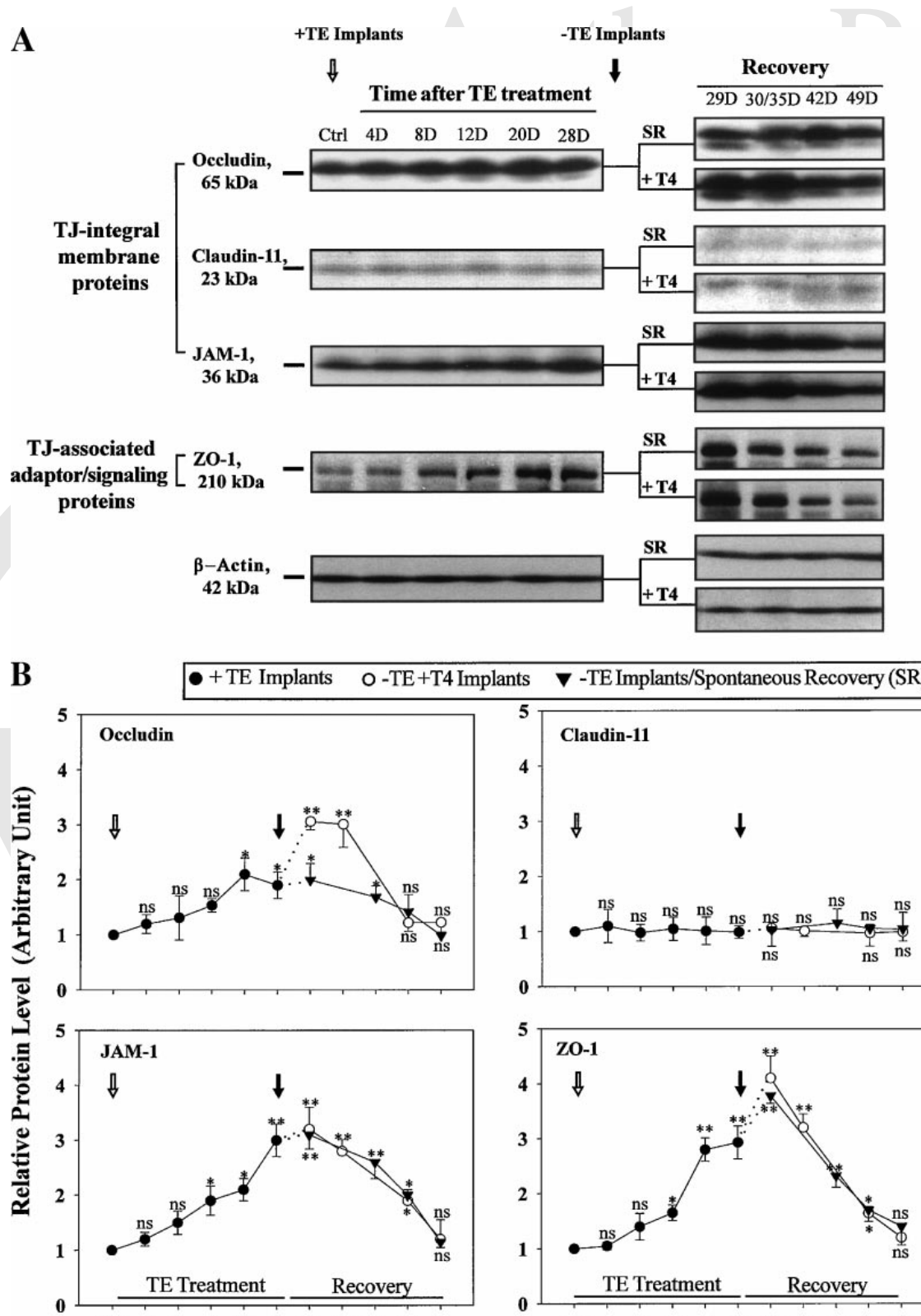

$\begin{array}{lllllllllll}\text { Ctrl } & 4 & 8 & 12 & 20 & 28 & 29 & 30 & 35 & 42 & 49\end{array}$

\section{Time after treatment (days)}

Fig. 2. A, B: A study by immunoblotting to assess changes in TJassociated proteins in the rat testis during androgen suppressioninduced germ cell loss and its recovery. A: Immunoblotting results in which lysates of testes containing $\sim 150 \mu \mathrm{g}$ protein from each sample within an experimental group were resolved by SDS-PAGE, and the blots were probed with different primary antibodies. Immunoblot data were arranged into two groups: androgen depletion induced by TE implants and the two recovery groups. In the recovery phase, the column labeled as $30 / 35 \mathrm{D}$ represents recovery under high $\mathrm{T}$ condition on day 30 or spontaneous recovery on day 35 . The bottom part is the same blot as those shown above, but reprobed with an anti-actin antibody to assess equal protein loading. B: These are densitometrically-scanned data using immunoblots such as those shown in (A). All data were normalized against $\beta$-actin to account for uneven protein loading and the level of a target protein in control rats was arbitrarily set at 1 . Each data point is the mean $\pm \mathrm{SD}$ of three rats. ns, not significantly different from control as determined by ANOVA; * significantly different, $P<0.05 ; * *$, significantly different, $P<0.01$.
Cheng, 2004a,b; Siu and Cheng, 2004a,b): the cadherin/ catenin complex, the nectin/afadin complex, and the integrin/laminin complex. Thus, these proteins were selected to examine changes in their levels during androgen suppression-induced germ cell loss to assess AJ disruption (Fig. 5). All cadherins and catenins were induced in the testis during androgen suppressioninduced germ cell loss, which declined thereafter in both recovery groups and returned to control levels (Fig. 5A,B). N-Cadherin, $\alpha$-catenin, and $\beta$-catenin, apparently sharing a common pattern of changes in protein levels, were induced by almost four- to fivefold of the control by days 28-30 after TE treatment (Fig. 5A). A noted exception is E-cadherin, which protein level was reduced after TE treatment, but returned to that of normal testes at the end of recovery (Fig. 5A,B). l-Afadin and integrin- $\beta 1$ protein levels (Fig. 5A,B) displayed a pattern similar to $\mathrm{N}$-cadherin, $\alpha$-catenin, and $\beta$-catenin which were induced during germ cell loss but subsided thereafter during recovery. Like E-cadherin, nectin-3 protein level declined when spermatids were depleted from the seminiferous epithelium during $\mathrm{TE}$ treatment 


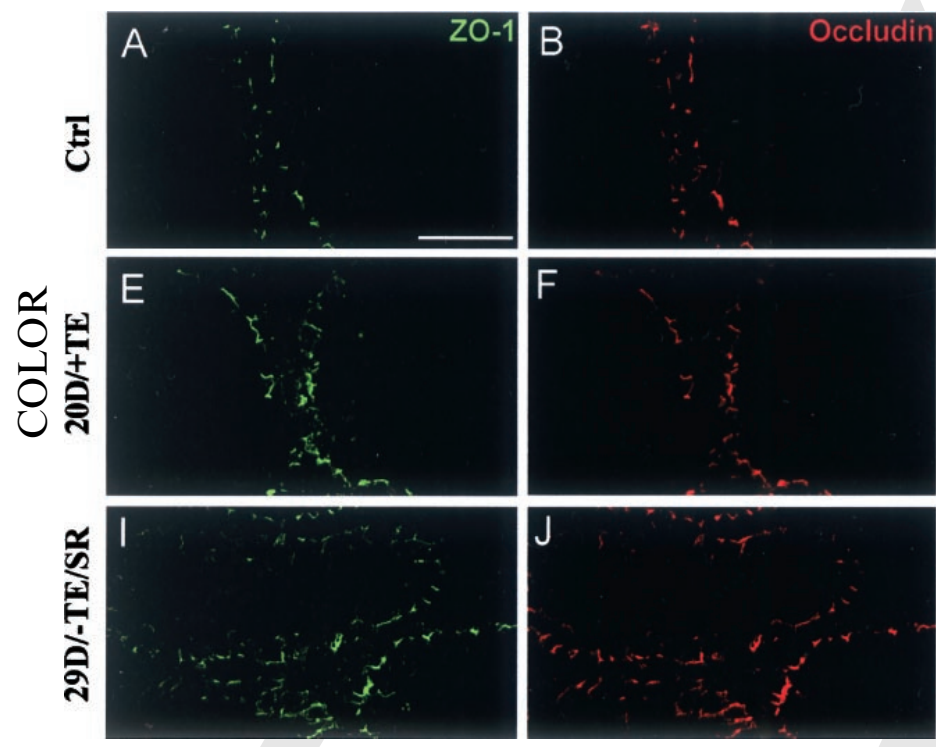

Fig. 3. A-L: An assessment of the BTB integrity in rat testes by immunofluorescent microscopy during androgen suppression-induced germ cell loss from the seminiferous epithelium. A-D, control testes; $\mathrm{E}-\mathrm{H}$, testes of rats with TE implants for 20 days $(20 \mathrm{D} /+\mathrm{TE})$; I-L, testes of rats terminated on day 29 in spontaneous recovery group

and returned to the level of normal testes in the recovery phase (Fig. 5A,B). Laminin- $\gamma 3$ showed no obvious changes in its protein level (Fig. 5A,B).

$\mathrm{N}$-cadherin and $\beta$-catenin diffuse away from the BTB site, dissociating from each other during androgen suppression-induced germ cell loss from the epithelium. Most of the AJ-associated proteins examined displayed a pattern of induction during germ cell loss from the epithelium, such as cadherins, catenins, afadins, and integrin- $\beta 1$ (see Fig. 5A,B). For those that were downregulated, such as E-cadherin and nectin-3, their losses may have weakened adhesion between Sertoli and germ cells, leading to germ cell loss from the epithelium. The observation that an induction of AJ-proteins can still lead to a loss of cell adhesion function is unexpected (see Figs. $4 \mathrm{~B}$ and 5). We hypothesize that such an induction may be a physiological response of the epithelium in the testis to the declining endogenous testosterone level, trying to retain the depleting spermatids. To investigate how these germ cells lost their ability to adhere to the epithelium, we performed two additional experiments. First, we sought to examine the pattern of distribution of $\mathrm{N}$ cadherin and $\beta$-catenin in the seminiferous epithelium using fluorescence microscopy during androgen suppression-induced germ cell loss (Fig. 6A). In control rat testes, $\mathrm{N}$-cadherin and $\beta$-catenin co-localized to the same site in the basal compartment consistent with their localization at the BTB (Fig. 6A, parts a-d). Interestingly, there was evidence that a thickening of the belt-like fluorescent immunostaining of both $\mathrm{N}$ cadherin and $\beta$-catenin had occurred during germ cell loss induced by androgen suppression using TE implants (see white square bracket in Fig. 6A, parts a, $\mathrm{e}, \mathrm{i}$, and $\mathrm{m}$ ); and this staining became diffused from the BTB site. Figure $6 \mathrm{~B}$ summarized the result of an analysis quantifying the $\mathrm{RD}$ of $\mathrm{N}$-cadherin and $\beta$ catenin from BTB in epithelium during androgen suppression-induced germ cell loss versus control rats, illustrating a significant increase in protein diffusion. Second, we speculated that such an increase in the diffusion of $\mathrm{N}$-cadherin and $\beta$-catenin away from the
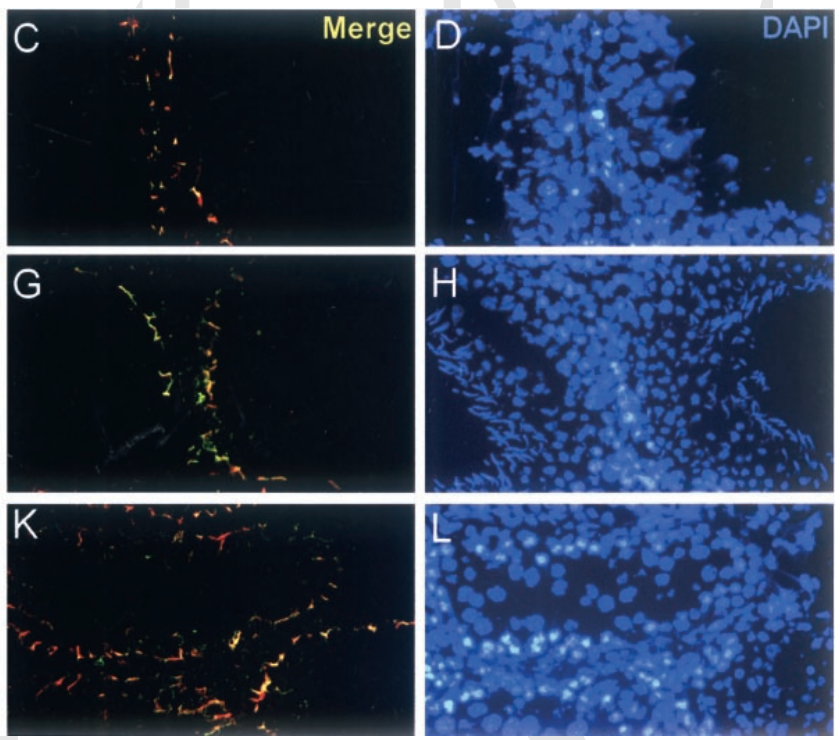

(29D/-TE/SR). A, E, I: ZO-1 staining (FITC-conjugated, green). B, F, J: Occludin staining (Cy3-conjugated secondary antibody, red). C, G, and $\mathrm{K}$ are the corresponding merged images of $\mathrm{A}$ and $\mathrm{B}, \mathrm{E}$ and $\mathrm{F}$, and $\mathrm{I}$ and $\mathrm{J}$ (yellowish-orange). D, H, L: DAPI staining. Bar $=80 \mu \mathrm{m}$ in (A), which applies to (B-L).

BTB site might reflect a loss of protein-protein association between $\mathrm{N}$-cadherin and $\beta$-catenin. We therefore sought to investigate this possibility by Co-IP experiments using an antibody against N-cadherin or $\beta$ catenin to pull down the corresponding protein in lysates and the blots were probed for $\beta$-catenin (Fig. 7A). The relative level of $\beta$-catenin in control testes versus samples from rats during androgen suppressioninduced germ cell loss from the epithelium detected in this Co-IP experiment using an anti- $\beta$-catenin antibody had a trend similar to that using lysates alone for immunoblotting, showing an induction at the time of germ cell loss (Fig. 7A,B). Yet using an anti-cadherin antibody for Co-IP, it failed to pull down more $\beta$-catenin at the time of germ cell loss (Fig. 7A), indicating that at the late stage of the TE treatment, this protein pair had weakened protein-protein association. The relative protein levels in the Co-IP experiment were normalized against control and plotted as a bar chart in Figure 7B. To estimate these results semi-quantitatively, the amount of $\beta$-catenin that was pulled down by the corresponding $\mathrm{N}$-cadherin or $\beta$-catenin antibody was compared and plotted as a scatter-line chart (Fig. 7B). It is noted that there was a $50 \%$ loss in protein-protein association between $\mathrm{N}$-cadherin and $\beta$-catenin at the time of germ cell loss (Fig. 7B vs. Fig. 4B). This result hence suggests that the loss of germ cells from the seminiferous epithelium may be the result of a loss of association between a cell adhesion protein (e.g., Ncadherin) with its adaptor (e.g., $\beta$-catenin) that led to a weakened or disrupted junction.

An increase in Tyr-phosphorylation of $\beta$-catenin may contribute to the cadherin/catenin protein complex dissociation. One mechanism that can account for the cadherin/catenin protein complex dissociation is Tyr-phosphorylation of the adaptor, $\beta$ catenin (for a review, see Daniel and Reynolds, 1997). To estimate the Tyr-phosphorylation status of $\beta$-catenin, we first used an anti- $\beta$-catenin antibody to pull down the target protein, which was resolved on SDSPAGE, electroblotted to nitrocellulose membrane and probed for a phosphor-Tyr antibody and detected an 
increase in Tyr-phosphorylation at the time of Sertoligerm cell adhesion impairment (day 20 and 30). However, the total Tyr-phosphorylation increase in $\beta$ catenin could be the result of an increase in $\beta$-catenin protein, which is known to occur during germ cell loss (see Figs. 5A, 6A, and 7A). To circumvent this issue, we had corrected uneven $\beta$-catenin protein level during androgen suppression-induced changes in the immunoprecipitated complexes as described in Materials and Methods (see part 3 in Fig. 8A vs. part 1). Interestingly,
A
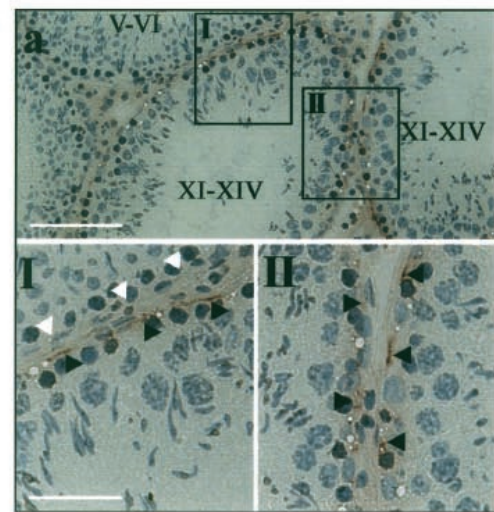

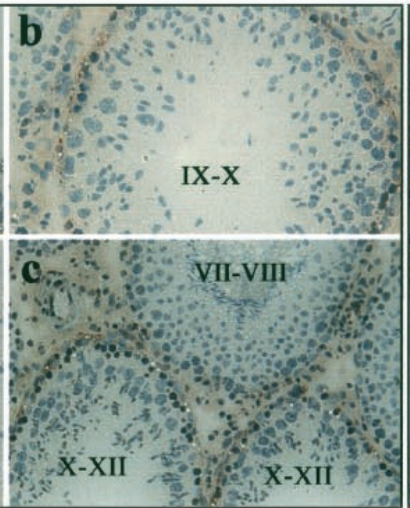

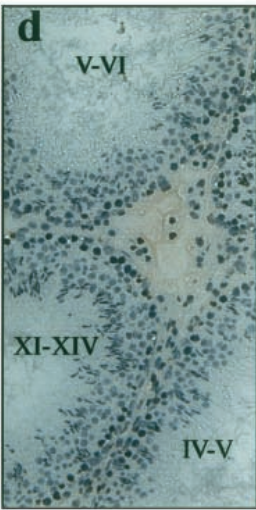

B
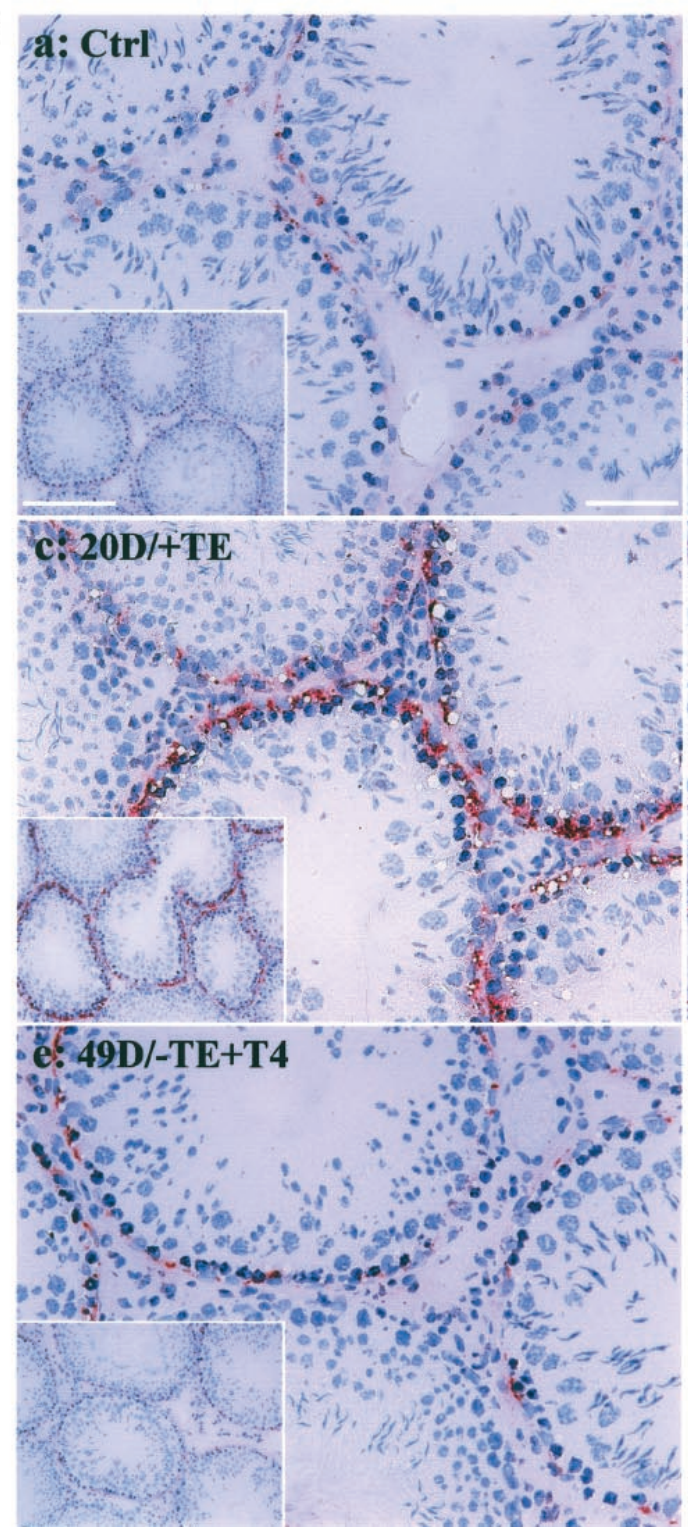
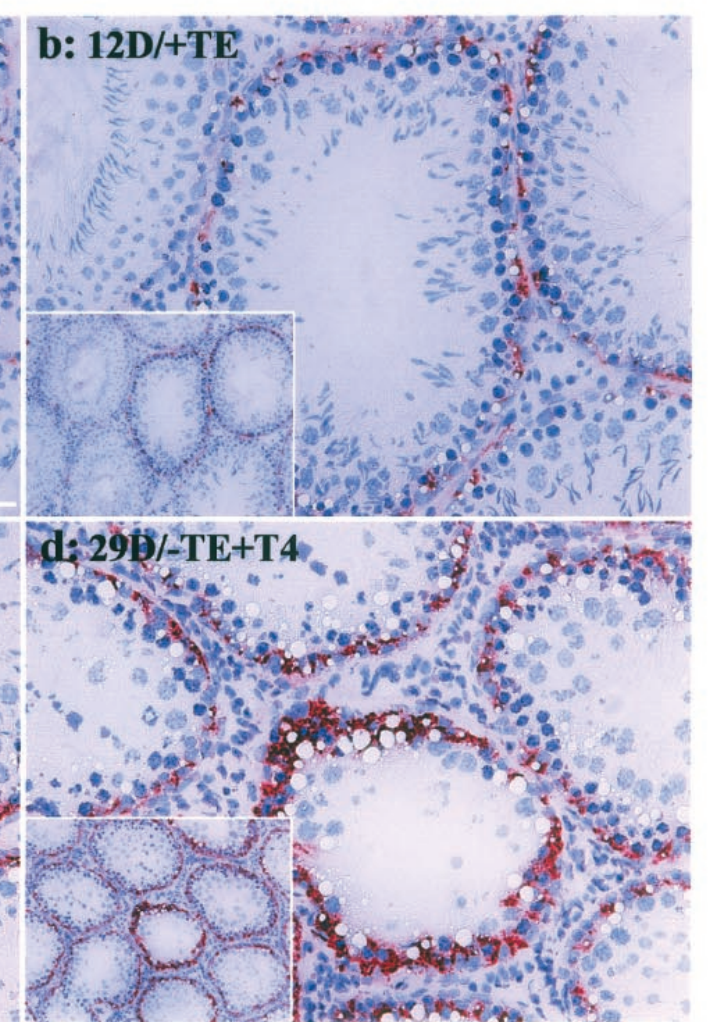

Fig. 4. 
C
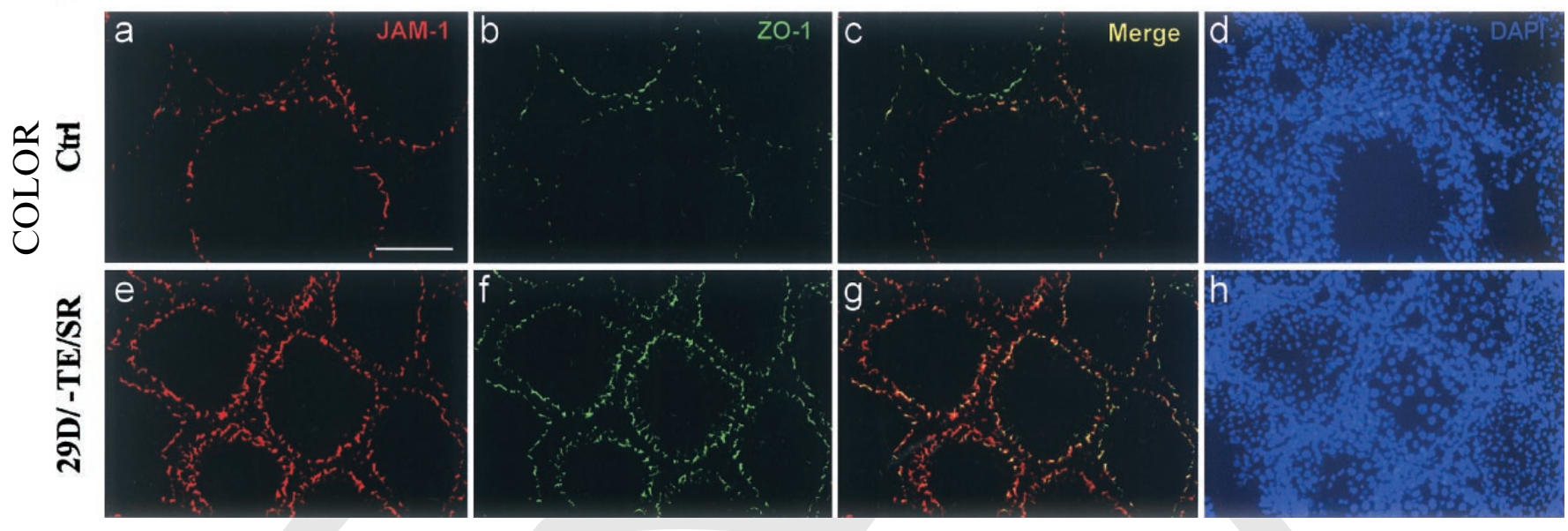

Fig. 4. (Continued)

an increase in Tyr-phosphorylation status in $\beta$-catenin was still detected (Fig. 8A,B). Figure 8 has thus illustrated an increase in Tyr-phosphorylation of $\beta$ catenin during germ cell loss from the epithelium.

\section{DISCUSSION}

Does a disruption of AJs in the seminiferous epithelium affect TJs, analogous to junctional complex disruption in other epithelia?

In this study, we have illustrated that a decline of intratesticular androgen level induced by TE implants can lead to a loss of adhesion function at the ES, leading to sloughing of spermatids (steps 8 and beyond) from the seminiferous epithelium, consistent with several earlier studies using this model (O'Donnell et al., 1996, 2000; Beardsley and O'Donnell, 2003). It was anticipated that TJs at the BTB would be compromised in this model since a disruption of AJs is known to perturb TJpermeability barrier function in virtually all other epithelia examined to date including skin, kidney, and intestine (Troxell et al., 1999; Man et al., 2000; Gassler et al., 2001; Venkiteswaran et al., 2002; Guo et al., 2003). Indeed, both $\mathrm{N}$-cadherin and $\beta$-catenin at the basal ES that co-exist with TJ in constituting the BTB were shown to be induced. However, a loss of their association was also detected by Co-IP experiment. Furthermore, both proteins at the basal ES apparently were diffusing away from the BTB site as detected by fluorescent microscopy consistent with biochemical study by Co-IP. Yet the BTB integrity was not compromised as illustrated by fluorescent microcopy. The technique of using fluorescent microscopy to monitor BTB integrity has been rigorously characterized in our laboratory in conjunction with electron microscopy and micropuncture technique assessing the leakage of $\left[{ }^{125} \mathrm{I}\right]$-BSA from the systemic circulation to the rete testis and seminiferous tubule fluids (Chung et al., 2001; Wong et al., 2004); and it was shown to be a reliable and sensitive approach to monitor the BTB integrity. It is apparent that the BTB integrity was maintained by a surge in the TJ-integral membrane proteins that constitute the TJ fibrils, such as occludin, JAM-1 and their common adaptor, ZO-1. This observation is physiologically significant, perhaps it is the same mechanism that is being used by the BTB to maintain the TJ integrity during extensive AJ restructuring pertinent to spermatogenesis. These data suggest that while the occludin/ZO-1, the JAM-1/ZO-1 and the cadherin/catenin protein complexes co-exist to constitute the BTB; at the time of AJ restructuring to facilitate germ cell movement during spermatogenesis, a disengagement of TJ (e.g., occludin/ZO-1) and AJ (e.g., cadherin/ catenin) proteins can occur, thereby allowing the induced TJ proteins to supersede the function of AJ proteins at the BTB and vice versa. This thus permits the loss of AJ function without compromising the BTB integrity.

Herein, we have shown that the three ES structural protein complexes, namely the cadherin/catenin, the nectin/afadin, and the integrin/laminin were induced preceding germ cell detachment from the epithelium as detected histologically. In some cases, the protein levels were induced as early as 4-12 days after insertion of TE implants, such as N-cadherin and catenins, with no obvious germ cell loss detected as yet. It is obvious that when germ cell loss was most severe on days 28-29, the protein induction was also most drastic. Needless to say, it can be argued that since T suppression by TE implants
Fig. 4. A-C: A study to assess the integrity of the BTB in the rat testis using JAM-1 as a TJ-marker protein by immunohistochemistry and fluorescent microscopy during androgen suppression-induced germ cell loss. A: Immunohistochemical localization of JAM-1 in normal rat testes. a-c, JAM-1 staining appears as reddish-brown precipitates. d, control staining using normal rabbit IgG, illustrating the staining shown in $(\mathrm{a}-\mathrm{c})$ is specific to JAM-1. Stages of the epithelial cycle were labeled. A magnified view of the boxed areas shown in (a) was also included and shown in I and II, in which black arrowheads indicate the JAM-1 staining which was found in the basal compartment near the basement membrane at the site consistent with its localization at the BTB (I and II) in stage XI-XIV tubules, and white arrowheads indicate the lack of JAM-1 staining in the same location in a stage V-VI tubule (I). These micrographs are representative results of four different experiments. Bar $=100 \mu \mathrm{m}$ in (a), which applies to $\mathrm{b}-\mathrm{d}$; bar $=50 \mu \mathrm{m}$ in (I), which applies to II. The immunoblot shown in (e) illustrates the specificity of JAM-1 antibody using lysates of testes and Sertoli cells since only a prominent band with an electrophoretic mobility of JAM-1 at $\sim 36-41 \mathrm{kDa}$ was detected. B: Immunohistochemical staining of JAM-1 in rat testes during androgen depletion-induced germ cell loss. a, normal testis; $\mathbf{b}$ and $\mathbf{c}$, testes from rats with TE implants for 12 days $(12 \mathrm{D} /+\mathrm{TE})$ and 20 days $(20 \mathrm{D} /+\mathrm{TE}) ; \mathbf{d}$, testis of rat in early recovery phase under high $\mathrm{T}$ condition after 1 day of TE implants removal with $4 \times \mathrm{T}$ implants inserted in this rat $(29 \mathrm{D} /-\mathrm{TE}+\mathrm{T} 4)$. Bar $=80 \mu \mathrm{m}$ in (a), which also applies to $(\mathrm{b}-\mathrm{d})$; and $\mathrm{bar}=320 \mu \mathrm{m}$ in the inset of (a), which applies to insets in $(b-d)$. C: Immunofluorescent co-localization of JAM1 and ZO-1 in normal and androgen-depleted testes. $\mathrm{a}-\mathrm{d}$, normal testis; $\mathbf{e}-\mathbf{h}$, testis of rat terminated on day 29 in the spontaneous recovery group (29D/-TE/SR) when the epithelium was virtually devoid of all spermatids (see B). a and e, JAM-1 staining revealed by a Cy3 conjugated goat anti-rabbit IgG (red); $\mathbf{b}$ and f, ZO-1 staining revealed by an FITC-conjugated mouse anti-ZO-1 antibody (green); $\mathbf{c}$ and $\mathbf{g}$, merged images of (a and b), (e and f), respectively (yellowish-orange); and $\mathrm{h}, \mathrm{DAPI}$ staining. Bar $=120 \mu \mathrm{m}$ in (a), also applicable to (b-g). 
causes testicular atrophy which is likely the result of loss of spermatids from the epithelium, as denoted by a reduction in testis weight to about $1 / 3$ to $2 / 5$ of that of control, proteins in Sertoli cells, spermatogonia, or spermatocytes might be "enriched" in the samples that were being analyzed instead of being physiologically "induced." If this is indeed the case, the level could plausibly be induced by 2.5 - to 3 -fold at the most. Yet in induction of $\sim$ five- to sixfold for these proteins were detected, illustrating that an increase in protein expression had indeed occurred. Furthermore, the induction of AJ-associated proteins was significantly higher than TJ proteins, arguing against the possibility that such changes are the result of a non-specific protein concentration effect as a result of declining testis weight. Nonetheless, such an increase in AJ proteins failed to retain germ cells in the epithelium since the association between these protein complexes, such as $\mathrm{N}$ cadherin and $\beta$-catenin, was significantly weakened as shown herein. The N-cadherin-associated $\beta$-catenin level which was pulled down using an anti-N-cadherin antibody by Co-IP was similar to the control level when

A

+TE Implants

-TE Implants
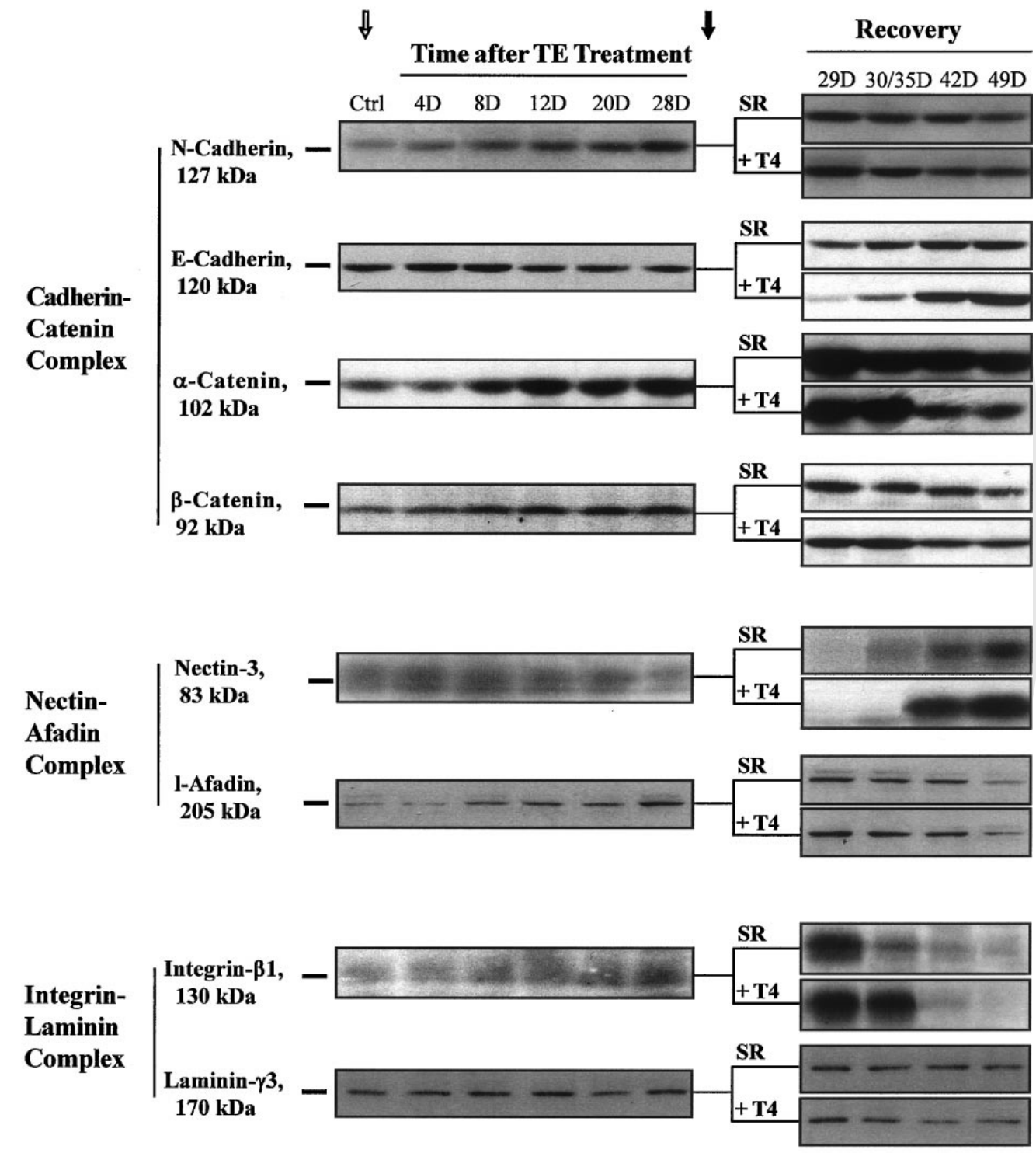
Cytoskeletal | $\beta$-Actin, protein $42 \mathrm{kDa}$

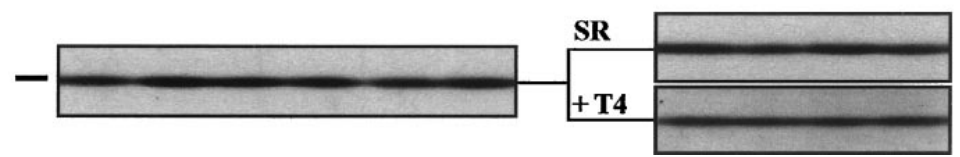

Fig. 5. A, B: A study by immunoblotting to assess changes in AJassociated proteins in rat testes during androgen suppression-induced germ cell loss from the seminiferous epithelium. A: Lysates of testes from rats of different treatment groups containing $\sim 150 \mu \mathrm{g}$ protein per lane was resolved by SDS-PAGE, electroblotted onto nitrocellulose papers and immunostained using different primary target antibodies. B: These are densitometrically-scanned data using immunoblots such as those shown in (A) with $n=3$ rats. The level of target protein in control rats (Ctrl) was arbitrarily set at 1 , against which all data were compared. Each data point is the mean $\pm \mathrm{SD}$ of three rats. ns, not significantly different from control as determined by ANOVA; *, significantly different, $P<0.05$; **, significantly different, $P<0.01$. Open arrowhead indicates where TE implants were placed in the dorsal region of the adult rats; solid arrowhead indicates where TE implants were removed, and rats were allowed to recover either spontaneously or with androgen implants. 


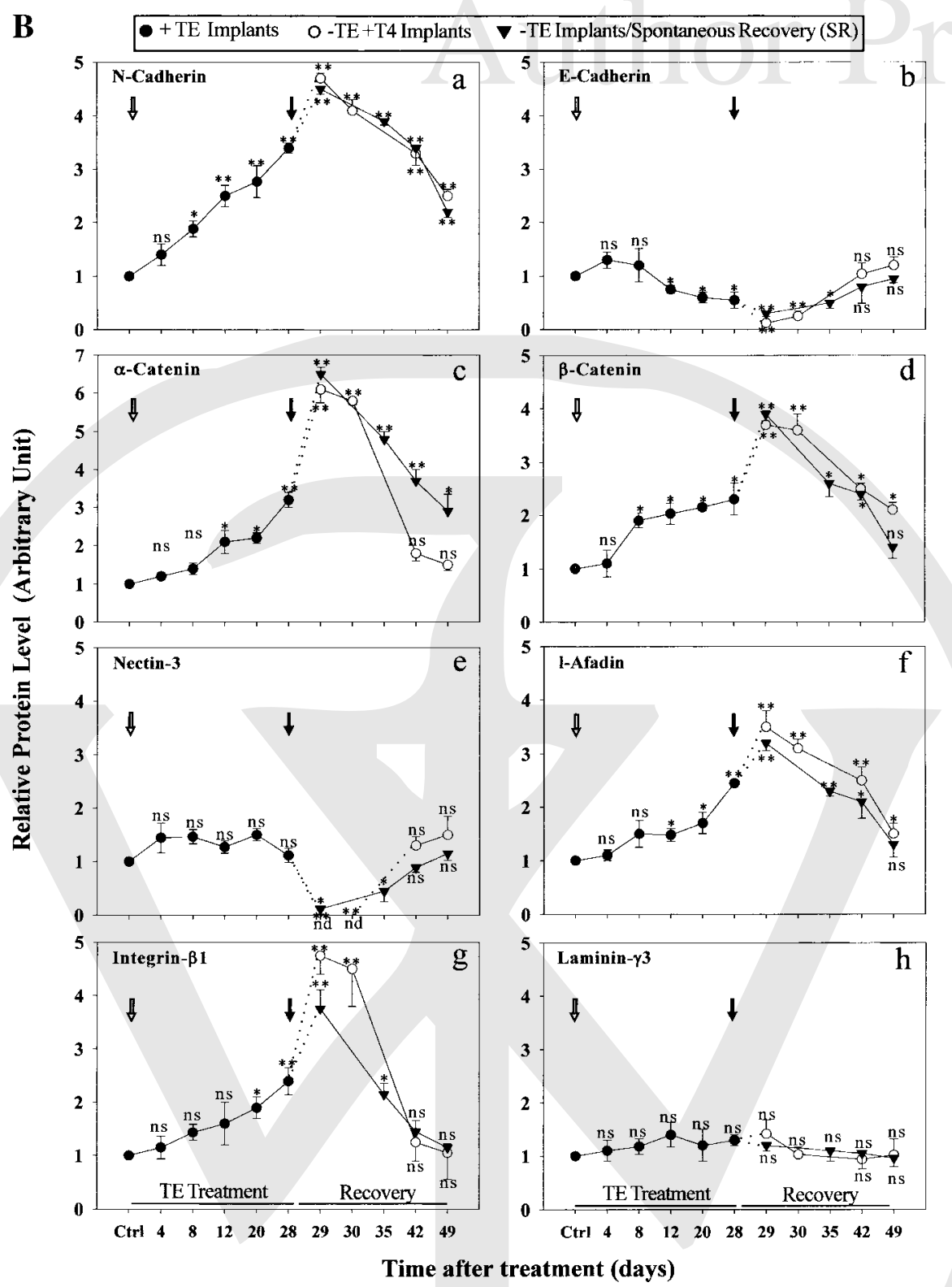

Fig. 5. (Continued)

its level was induced by almost five- to sixfold at the peak of germ cell loss from the epithelium. This is physiologically important since the $\mathrm{N}$-cadherin/ $\beta$-catenin complex is more predominant at the basal ES (Lee et al., 2003, 2004), and if basal ES structure was largely retained when spermatids were depleted from the epithelium on day 30 ( 2 days into the recovery phase), the N-cadherin antibody should pull down significantly more $\beta$-catenin than it was detected, taking testicular atrophy into account. This thus implies that there was an increase in the 'free,' non-N-cadherin-bound $\beta$ catenin pool in the cytoplasm of the testicular cells [e.g., both Sertoli cells, spermatogonia, and spermatocytes were shown to express both cadherins and catenins (Wu et al., 1993; Lee et al., 2003)], and a loss of $\mathrm{N}$-cadherin/ $\beta$-catenin association. This argument is indeed supported by results of fluorescence microscopy, which detected a diffusing localization pattern of these two proteins in the epithelium. It is likely that their loss of protein-protein association leads to a fuzzy, less focused localization at the BTB. What are the differences between the regulation
of epithelial TJ/AJ and TJ/basal ES at the BTB?

Current studies in epithelial cell physiology have shown that the assembly of TJs between epithelial cells requires the presence of $\mathrm{AJ}$, and changes in $\mathrm{AJ}$ integrity can modulate TJ formation and the epithelial permeability barrier function (Behrens et al., 1985; Troxell et al., 1999; Man et al., 2000; Guo et al., 2003). For instance, nectin-based adhesion is initially established between migrating epithelial cells, followed by cadherin-based adhesion to form mature AJs; thereafter JAMs, followed by claudin and occludin, are being recruited to the apical portion of AJ for assembling TJs (for reviews, see Takai and Nakanishi, 2003; Sakisaka and Takai, 2004), illustrating the intimate relationship between these junctions. When confluent epithelial cells are treated with agents that target specifically to AJ proteins (e.g., E-cadherin), both AJs and TJs can be compromised, as manifested by an increase in permeability function (Fujimori and Takeichi, 1993; Man et al., 2000). 

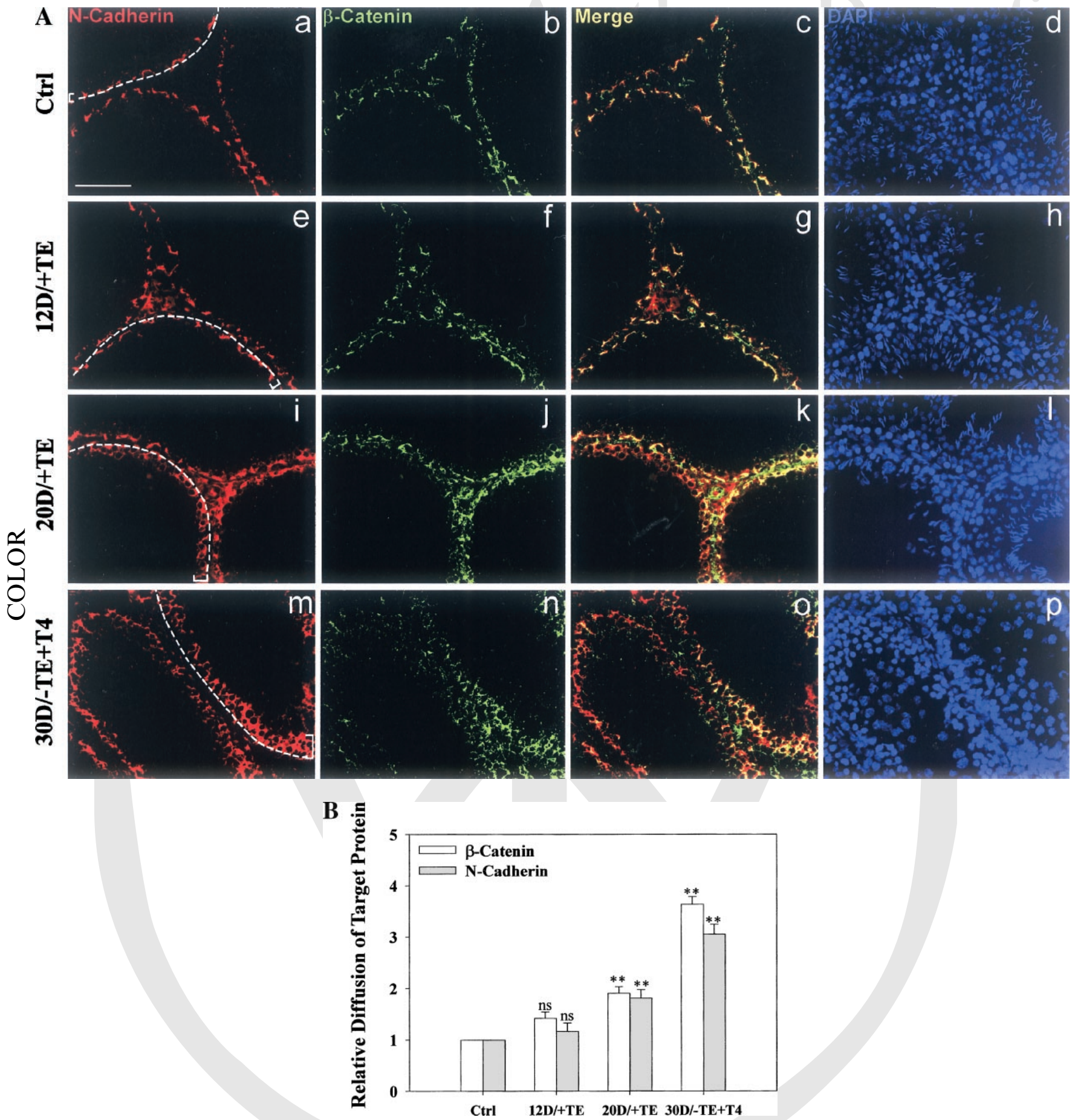

Fig. 6. A, B. A study to assess changes in the pattern of localization of $\mathrm{N}$-cadherin and $\beta$-catenin in the seminiferous epithelium and their apparent loss of association by immunofluorescence microscopy during androgen suppression-induced germ cell loss from the testis. A: Immunofluorescent co-localization of $\mathrm{N}$-cadherin and $\beta$-catenin to the epithelium in rat testes during androgen suppression-induced germ cell loss. $\mathbf{a}-\mathbf{d}$, control testes; $\mathbf{e}-\mathbf{h}$, testes of rats with TE implants for 12 days $(12 \mathrm{D} /+\mathrm{TE})$; $\mathbf{i}-\mathbf{l}$, testes of rats after 20 days of TE treatment $(20 \mathrm{D} /+\mathrm{TE}) ; \mathbf{m}-\mathbf{p}$, testes of rats terminated on day 30 with 28 days of TE treatment followed by 2 days of recovery under high T condition $(30 \mathrm{D} /-\mathrm{TE}+\mathrm{T} 4)$ when the seminiferous epithelium was virtually devoid of round, elongating, and elongate spermatids (see Fig. 3B). $\mathrm{a}, \mathrm{e}, \mathrm{i}, \mathrm{m}$ : N-cadherin staining (Cy3, red); $\mathrm{b}, \mathrm{f}, \mathrm{j}, \mathrm{n}$ : $\beta$-catenin staining (FITC, green); c, g, k, and o are the corresponding merged images of (a and $b$ ), (e and f), (i and j), ( $m$ and $n$ ) (yellowish-orange); $d, h, l, p$ : DAPI staining. Bar $=100 \mu \mathrm{m}$ in (a), which also applies to $(b-p)$. White broken line indicates the location of the basal compartment corre-

sponding to the BTB site nearing the basement membrane in (a, e, i, $\mathrm{m}$ ); and the "bracket" indicates the RD of a target AJ-protein during androgen depletion-induced germ cell loss from the epithelium. B: This bar chart shows the RD of N-cadherin or $\beta$-catenin from its site of origin near the basement membrane. This is calculated by measuring the distance of the fluorescence that moved away from the BTB site indicated by the white broken line. As seen in ( $a$ and $b$ ), virtually all the immunoreactive $\mathrm{N}$-cadherin and $\beta$-catenin resided closely to the white broke line in the basal compartment, which diffused away from the basal ES at BTB as shown in testes from time points at $12 \mathrm{D} /+\mathrm{TE}$ $20 \mathrm{D} /+\mathrm{TE}$, and $30 \mathrm{D} /-\mathrm{TE}+\mathrm{T} 4$. The distance of target protein that diffused away was compared to control testis (mean), which was arbitrarily set at 1 . Each data point is the mean \pm SD $(n=50$ tubules scored from at least two testes of different rats). ns, not significantly different from control as determined by ANOVA; **, significantly different, $P<0.01$. 
A
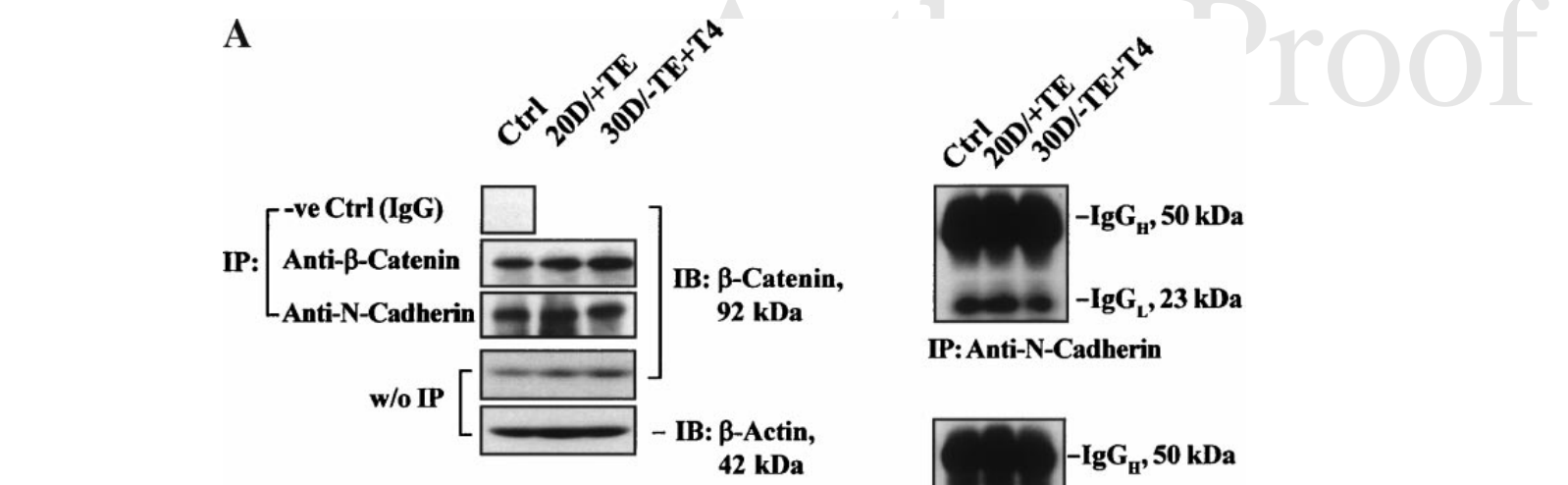

IP: Anti-N-Cadherin

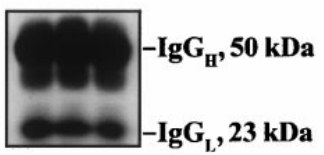

IP: Anti- $\beta$-Catenin

B

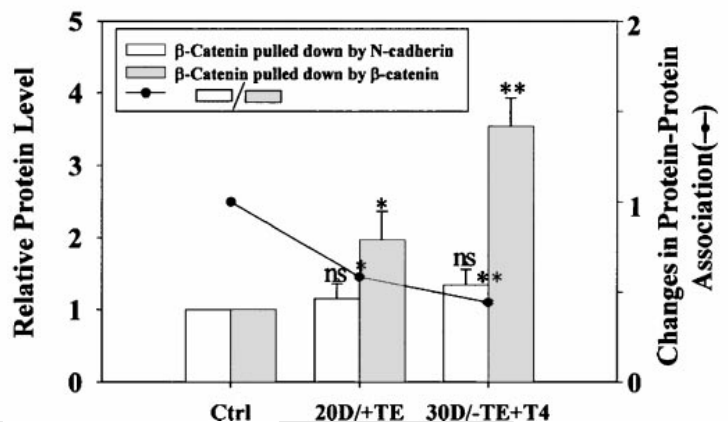

Fig. 7. A, B: A study by Co-IP to assess changes in protein-protein interactions of the $\mathrm{N}$-cadherin- $\beta$-catenin protein complex in rat testes during androgen suppression-induced germ cell loss from the seminiferous epithelium. A: Equal amount of lysates ( $\sim 500 \mu \mathrm{g}$ protein $)$ from control, $12 \mathrm{D} /+\mathrm{TE}$, and $30 \mathrm{D} /-\mathrm{TE}+\mathrm{T} 4$ testes were IP using an anti-N-cadherin or an anti- $\beta$-catenin antibodies. The immunoprecipitated complexes were analyzed by immunoblotting (IB) using a specific $\beta$-catenin antibody to estimate if there was a loss of proteinprotein association in the cadherin/catenin complex. A negative control was also included in which the precipitating antibody was substituted by rabbit IgG. Following SDS-PAGE, proteins were detected by immunoblotting using an anti- $\beta$-catenin antibody. An aliquot of lysates used for IP were also probed for $\beta$-actin to assess if

This suggests that the proximity of AJ and TJ between epithelial cells has created a bi-directional cross-talk mechanism that a disruption of one junction type can transmit the disruptive signal to the other. If a similar mechanism(s) is in place in the seminiferous epithelium, the BTB integrity cannot be maintained at spermatogenesis when thousands of developing germ cells have to traverse the epithelium throughout the epithelial cycle, associating with extensive junction restructuring (for reviews, see Cheng and Mruk, 2002; Mruk and Cheng, 2004a).

Based on the data presented herein plus those found in the literature, it remains unclear regarding the intricate coordination of TJs and basal ES to facilitate germ cell movement. Yet the present study has clearly illustrated that, unlike other epithelia, the basal/apical ES cell adhesion function and the TJ barrier function can be "disengaged" so as to maintain the BTB integrity. For instance, during the androgen suppression-induced spermatids loss from the epithelium, signals that induce disruption of apical ES are being shielded from affecting TJ integrity, but not basal ES, at the BTB. In fact, these signals possibly reinforce the basal barrier function. This conclusion was reached based on the fact that both equal amount of protein was used. The right part shows the heavy and light chains of IgG following IP from the same immunoblots shown on the left part to illustrate equal protein loading and uniform protein transfer. A surge in $\beta$-catenin using lysates without (w/o) IP was detected. While total $\beta$-catenin pulled down by the anti- $\beta$-catenin antibody is consistent with the lysate data (see w/o IP), the anti-Ncadherin failed to pull out the same amount of $\beta$-catenin, illustrating a loss of protein-protein interaction. B: This bar chart was prepared using data such as those shown in (A) that were densitometrically scanned, and normalized to the control testis, which was arbitrarily set at 1 . Each data point is the mean \pm SD from three experiments. ns, not significantly different from control as determined by ANOVA; **, significantly different, $P<0.01$.

TJ and AJ proteins were induced at the time of spermatid loss. Yet $\mathrm{N}$-cadherin and $\beta$-catenin at the basal ES were found to diffuse away from the BTB site, apparently disengaging from the adjacent TJ-protein complexes (e.g., the occludin/ZO-1 and the JAM-1/ZO-1 protein complexes) so that the TJ-barrier function was not compromised. This disengagement mechanism can thus permit the loss of spermatids from the epithelium because of a loss of the cadherin/catenin function that confers cell adhesion (via a loss of protein-protein interactions) while leaving the significantly induced proteins of the occludin-ZO-1 and the JAM-1-ZO-1 complexes at the BTB site to maintain the TJ-barrier function.

Recent studies have shown that TJ and AJ of gastrointestinal epithelial cells can be disrupted by progastrin hormone through activation of Src and PI 3kinase, respectively. However, blocking either signal transducer failed to rescue the other junction type from disruption (Hollande et al., 2003). In Madin-Darby canine kidney cells, EGTA treatment-induced junction disruption involved a transition of ZO-1 association with TJ proteins occludin and claudin to AJ protein E-cadherin (Rothen-Rutishauser et al., 2002). These 

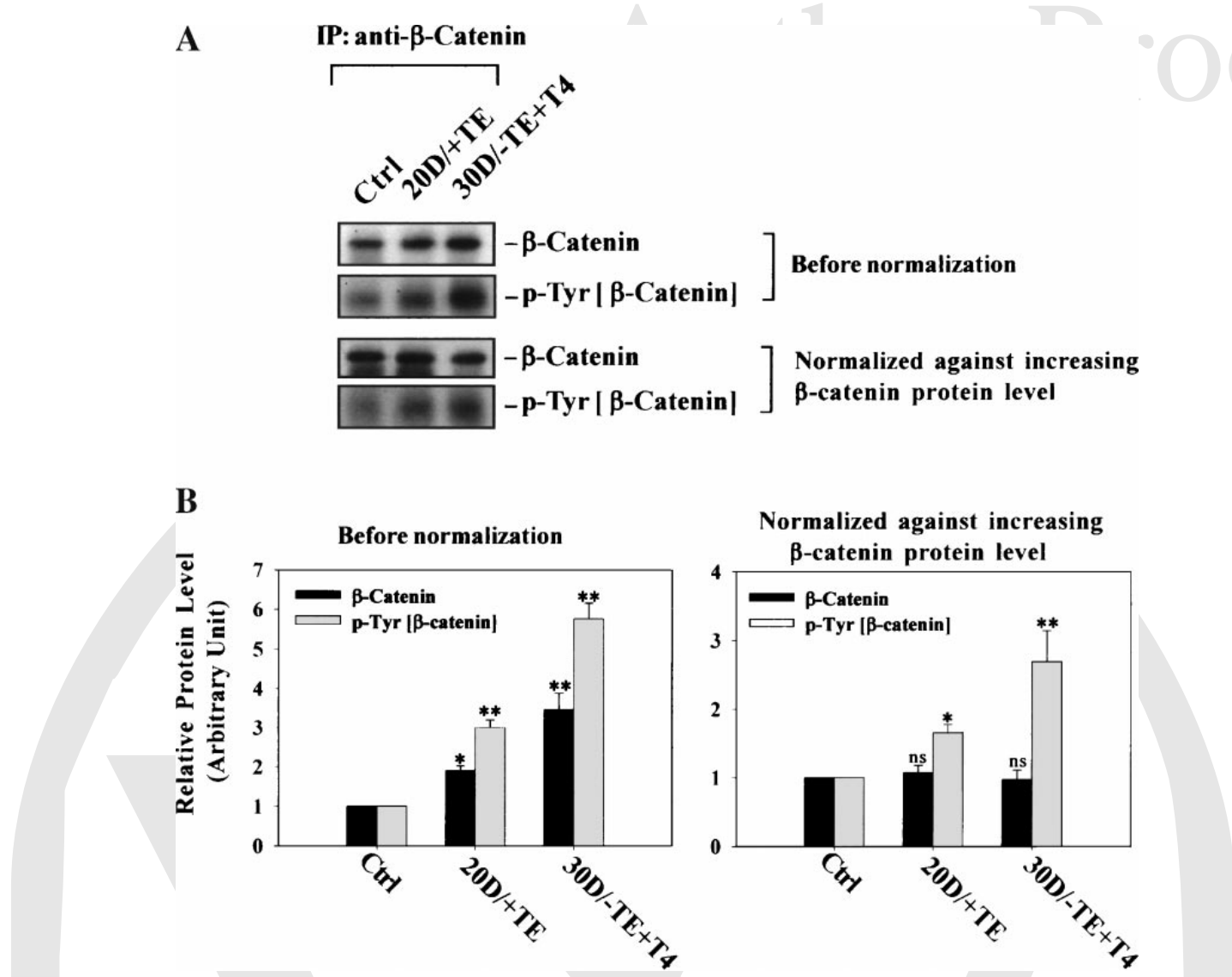

Fig. 8. A, B: A study to assess changes in the level of Tyrphosphorylation of $\beta$-catenin in rat testes during androgen suppression-induced germ cell loss. A: To examine changes in Tyr-phosphorylation in $\beta$-catenin, sample lysates $(\sim 1,200 \mu \mathrm{g})$ from control (Ctrl), $12 \mathrm{D} /+\mathrm{TE}$, and $30 \mathrm{D} /-\mathrm{TE}+\mathrm{T} 4$ testes were IP using an anti- $\beta$-catenin antibody. Immunocomplexes after IP were divided into three equal aliquots as follows. The first aliquot (1/3) was examined by immunoblotting using an anti- $\beta$-catenin antibody (top part). This blot was stripped and reprobed with an anti-phospho-Tyr antibody illustrating an increase in Tyr-phosphorylation (p-Tyr) (2nd part). As such, both top and 2nd parts are results obtained before normalization against changes in $\beta$-catenin protein. But since there was an increase in $\beta$-catenin per se (see top part), the increase shown in the second part could be attributed to an increase in $\beta$-catenin protein.

results seemingly suggest that epithelial AJ and TJ disassembly, although interdependent with each other, is regulated via different signaling pathways. Furthermore, the shift of association between ZO-1, occludin/ claudin, and E-cadherin also supports the disengagement hypothesis ascribed to BTB regulation. It is apparent that if adequately sealed within a microenvironment, the disruption of one junction type can be restricted without spreading over to others. An interesting question remains to be addressed: is this indeed the case in the testis? In the testis, several signaling pathways have been identified that are crucial to AJ dynamic regulation, by and large at the apical ES, which include the integrin/pFAK/PI 3-K/p130 Cas/ERK and the integrin/RhoB/ROCK/LIMK/cofilin pathways (Lui et al., 2003a; Siu et al., 2003b), whereas TJ dynamics are mediated via the TGF- $33 / \mathrm{MEKK} 2 / \mathrm{p} 38$ MAPK and integrin/ILK/GSK-3/p130 Cas/JNK pathways (Lui et al., 2003b; Siu et al., 2003a). Some of these signaling pathways may act specifically to one junction type but some seem to be more versatile. For instance, the TGF$\beta 3 /$ p38 MAPK was found to regulate both AJ and TJ dynamics (Wong et al., 2004). Interestingly, TGF- $\beta 3$ was
The blot in top part was therefore scanned and the protein level of $\beta$ catenin was normalized and the other $1 / 3$ aliquot was used for a second immunoblotting experiment. The third part shows the IP products of $\beta$-catenin after it was normalized against the increase in $\beta$-catenin level. As such, the level of $\beta$-catenin between samples was uniform (3rd part). When this blot was stripped and reprobed with an antiphospho-Tyr antibody, an increase in Tyr-phosphorylation indeed was detected (bottom part), showing a surge in $\beta$-catenin phosphorylation. B: This bar chart was prepared using immunoblotting data, such as those shown in (A), which were densitometrically scanned, and normalized to control testes, which was arbitrarily set at 1. Each data point is the mean $\pm \mathrm{SD}$ from three experiments. ns, not significantly different from control as determined by ANOVA; **, significantly different, $P<0.01$.

recently shown to disrupt Sertoli-germ adhesion function at the AJ without affecting the TJ integrity at the BTB (Xia and Cheng, 2005). Thus, the testis is equipped with different transducers that are capable of directing multiple signaling pathways to regulate diversified functions pertinent tojunction dynamics, but the details of how these signals are being utilized remain unexplored. Nonetheless, these findings illustrate the seminiferous epithelium is using a different strategy to regulate junction dynamics pertinent to spermatogenesis versus other epithelia.

\section{Phosphorylation of adaptor proteins caused dissociation of cell adhesion complex}

Although it has been known for almost a decade that phosphorylation of cadherins and $\beta$-catenin can alter the adhesive function of AJ (for reviews, see Daniel and Reynolds, 1997; Gumbiner, 2000), yet this possibility has not been explored in the testis until recently (Wine and Chapin, 1999; Chapin et al., 2001; Lui et al., 2003a). In this study, we have demonstrated unequivocally that an increase in Tyr-phosphorylation of $\beta$-catenin 


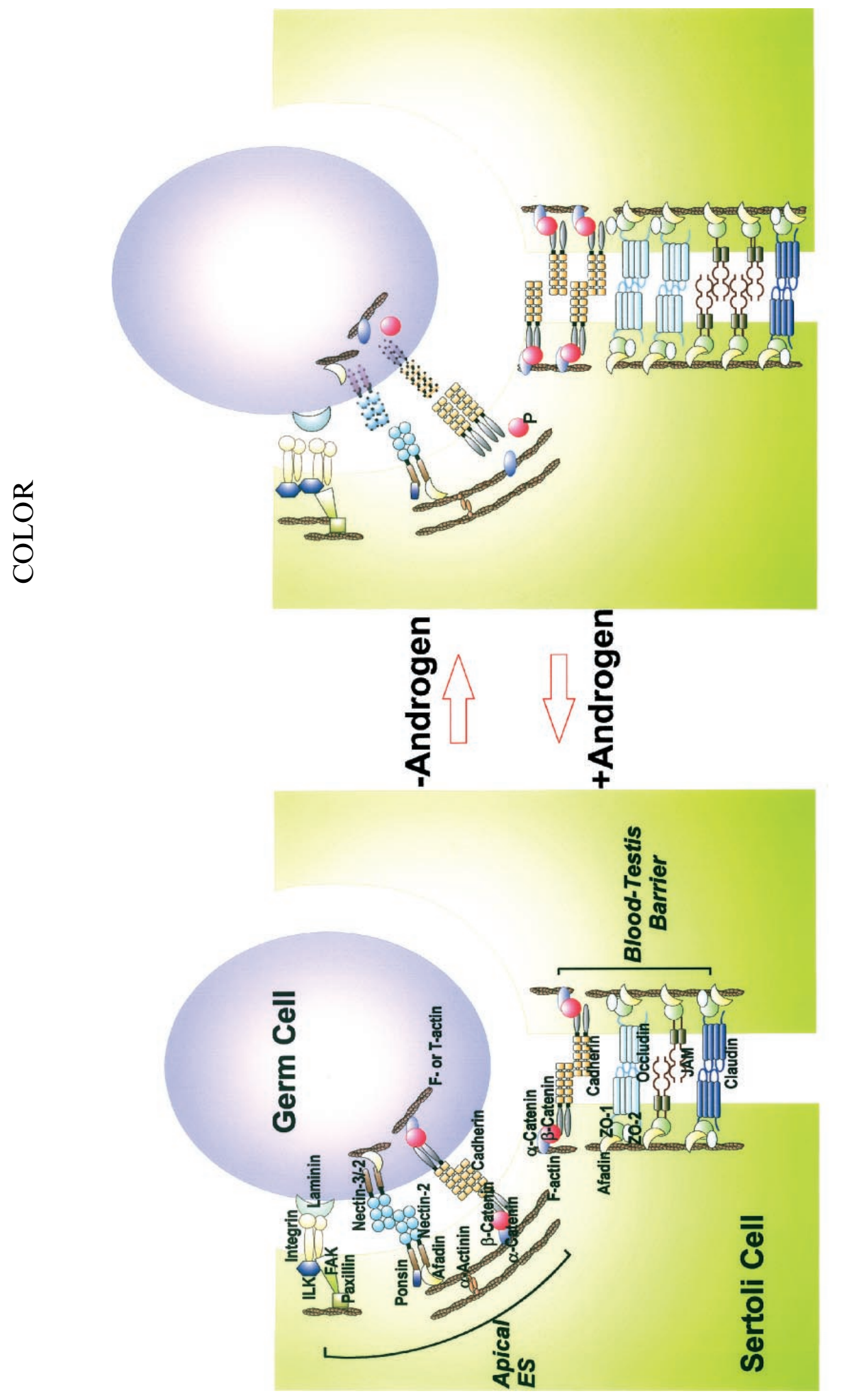

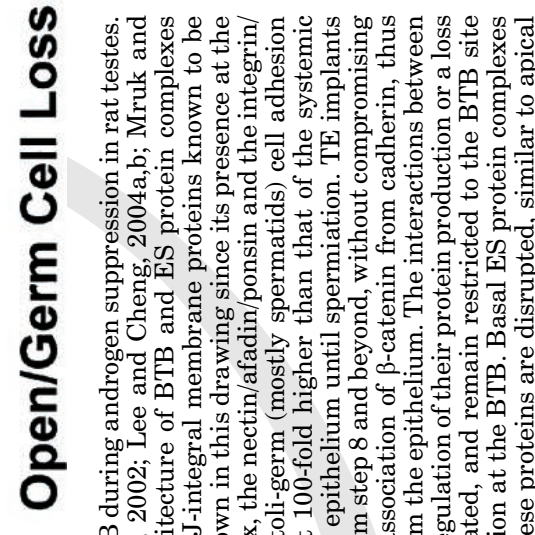

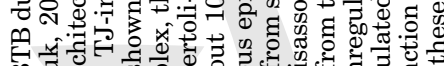

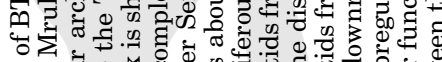
ఖ

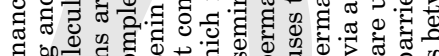
व

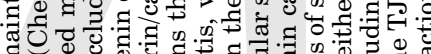

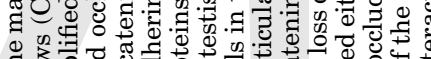

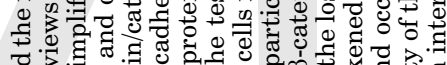

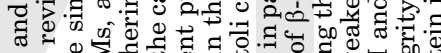
की

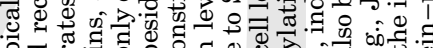
क्षे ๘ँ ส

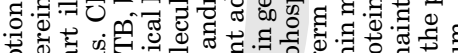

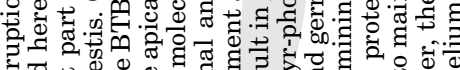

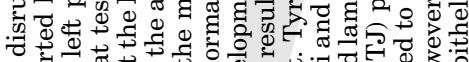

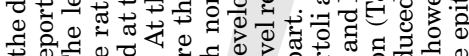

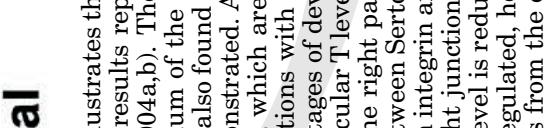

(U)

E

- To (1) \$ 0 . 0

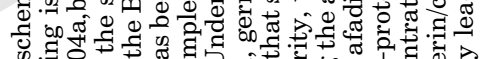
《. o

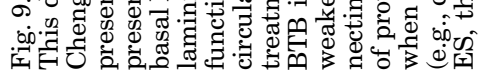


occurred at the time of a weakened $\mathrm{N}$-cadherin/ $\beta$ catenin association, leading to spermatid detachment from the epithelium. Earlier studies have implicated the roles of protein phosphorylation in the regulation of spermiation (Wine and Chapin, 1999; Chapin et al., 2001). Using AF-2364 [1-(2,4-dichlorobenzyl)-indazole3-carbohydrazide] to induce germ cell depletion from the epithelium, it has been shown that germ cell loss is also accompanied by an induction of $\mathrm{N}$-cadherin and $\beta$ catenin, and other peripheral ES proteins such as Fer kinase, pFAK, p130Cas (Chen et al., 2003; Lee et al., 2003; Siu et al., 2003b). For instance, the cadherin/ catenin complex was shown to associate with several protein kinases including c-Src, CK2, Csk and Fer, and adaptors (e.g, WASP, axin, zyxin) that link the protein complex to the underlying actin cytoskeleton (Chen et al., 2003; Lee and Cheng, 2005). Similar to earlier studies using the AF-2364 model, we speculate that these kinases are involved in the loss of spermatids from the epithelium when a surge in Tyr-phosphorylation of $\beta$-catenin occurs, thereby the cadherin and catenin proteins not only dissociate from each other but also from the actin cytoskeleton.

\section{Summary and concluding remarks}

In summary, a disruption of AJ (e.g., ES) in the androgen suppression model is limited to the apical and basal ES without affecting the BTB integrity, implicating the testis is able to direct the regulatory signals to a junction site specifically via a disengagement mechanism. Based on the results reported herein, we propose a schematic model shown in Figure 9 that regulates ES and TJ function in the rat seminiferous epithelium. It is of interest to note that both apical ES and basal ES at the Sertoli cell side are similar in structure except that basal ES co-exist with TJ at BTB. But how can a signal that targets the disassembly of apical ES and basal ES can limit its action at ES without perturbing the adjacent TJ-barrier? While this is likely via a disengagement mechanism as illustrated herein, it remains to be investigated how this signal is being transmitted between basal ES and TJ at the BTB, and between BTB and apical ES.

\section{ACKNOWLEDGMENTS}

This study is supported in part by grants from the National Institutes of Health (NICHD, U01 HD045908 to C.Y.C.; and U54 HD029990, Project 3 to C.Y.C.), and the CONRAD Program (CICCR, CIG 01-72 to C.Y.C.).

\section{LITERATURE CITED}

Alberts B, Johnson A, Lewis J, Raff M, Roberts K, Watter P. 2002. Molecular biology of the cell. New York: Garland Science.

Bazzoni G, Martinez-Estrada O, Orsenigo F, Cordenonsi M, Citi S, Dejana E. 2000. Interaction of junctional adhesion molecule with the tight junction components ZO-1, cingulin, and occludin. J Biol Chem 275:20520-20526.

Beardsley A, O'Donnell L. 2003. Characterization of normal spermiation and spermiation failure induced by hormone suppression in adult rats. Biol Reprod 68:1299-1307.

Behrens J, Birchmeier W, Goodman S, Imhof B. 1985. Dissociation of MadinDarby canine kidney epithelial cells by the monoclonal antibody anti-arc-1: Mechanistic aspects and identification of the antigen as a component related to uvomorulin. J Cell Biol 101:1307-1315.

Braga VM. 2002. Cell-cell adhesion and signaling. Curr Opin Cell Biol 14:546-556. Chapin RE, Wine RN, Harris MW, Borchers CH, Haseman JK. 2001. Structure and control of a cell-cell adhesion complex associated with spermiation in rat seminiferous epithelium. J Androl 22:1030-1052.

Chen YM, Lee NPY, Mruk DD, Lee WM, Cheng CY. 2003. Fer kinase/FerT and adherens junction dynamics in the testis: An in vitro and in vivo study. Biol Reprod 69:656-672.

Cheng CY, Mruk DD. 2002. Cell junction dynamics in the testis: Sertoli-germ cell interactions and male contraceptive development. Physiol Rev 82:825-874.

Chung NPY, Mruk D, Mo M-Y, Lee WM, Cheng CY. 2001. A 22-amino acid synthetic peptide corresponding to the second extracellular loop of rat occludin perturbs the blood-testis barrier and disrupts spermatogenesis reversibly in vivo. Biol Reprod 65:1340-1351.
Daniel JM, Reynolds AB. 1997. Tyrosine phosphorylation and cadherin/catenin function. BioEssays 19:883-891.

Dym M. 1994. Basement membrane regulation of Sertoli cells. Endocr Rev 15:102-115.

Fujimori T, Takeichi M. 1993. Disruption of epithelial cell-cell adhesion by exogenous expression of a mutated nonfunctional N-cadherin. Mol Biol Cell $4: 37-47$.

Gassler N, Rohr C, Schneider A, Kartenbeck J, Bach A, Obermuller N, Otto HF Autschbach F. 2001. Inflammatory bowel disease is associated with changes of enterocytic junctions. Am J Physiol Gastrointest Liver Physiol 281:G216G228.

Gumbiner BM. 2000. Regulation of cadherin adhesive activity. J Cell Biol 148:399-404.

Guo X, Rao JN, Liu L, Zou T-T, Turner DJ, Bass BL, Wang JY. 2003. Regulation of adherens junctions and epithelial paracellular permeability: A nove function for polyamines. Am J Physiol Cell Physiol 285:C1174-C1187.

Hollande F, Lee DJ, Choquet A, Roche S, Baldwin GS. 2003. Adherens junctions and tight junctions are regulated via different pathways by progastrin in epithelial cells. J Cell Sci 115:1187-1197.

Kamischke A, Nieschlag E. 2004. Progress towards hormonal male contraception. Trends Pharmacol Sci 25:49-57.

Kincl FA, Benagiano G, Angee I. 1968. Sustained release hormonal preparations-diffusion of various steroids through polymer membranes. Steroids 11:673-681.

Laemmli U. 1970. Cleavage of structural proteins during the assembly of the head of bacteriophage T4. Nature 227:680-685.

Lee NPY, Cheng CY. 2004a. Adaptors, junction dynamics, and spermatogenesis. Biol Reprod 71:392-404

Lee NPY, Cheng CY. 2004b. Ectoplasmic specialization, a testis-specific cell-cell actin-based adherens junction type: Is this a potential target for mal contraceptive development? Hum Reprod Update 10:349-369.

Lee NPY, Cheng CY. 2005. Protein kinases and adherens junction dynamics in the seminiferous epithelium of the rat testis. J Cell Physiol 202:344-360.

Lee NPY, Mruk D, Lee WM, Cheng CY. 2003. Is the cadherin/catenin complex a functional unit of cell-cell actin-based adherens junctions in the rat testis? Biol Reprod 68:489-508.

Lee NPY, Mruk DD, Conway AM, Cheng CY. 2004. Zyxin, axin, and WiskottAldrich syndrome protein are adaptors that link the cadherin/catenin protein complex to the cytoskeleton at adherens junctions in the seminiferou epithelium of therat testis. J Androl 25:200-215.

Lui WY, Lee WM, Cheng CY. 2003a. Sertoli-germ cell adherens junction dynamics in the testis are regulated by RhoB GTPase via the ROCK/LIMK signaling pathway. Biol Reprod 68:2189-2206.

Lui WY, Lee WM, Cheng CY. 2003b. Transforming growth factor-b3 regulates the dynamics of Sertoli cell tight junctions via the p38 mitogen-activated protein kinase pathway. Biol Reprod 68:1597-1612

Lui WY, Wong CH, Mruk DD, Cheng CY. 2003c. TGF-b3 regulates the bloodtestis barrier dynamics via the p38 mitogen activated protein (MAP) kinase pathway: An in vivo study. Endocrinology 144:1139-1142.

Man Y, Hart VJ, Ring CJA, Sanjar S, West MR. 2000. Loss of epithelial integrity resulting from E-cadherin dysfunction predisposes airway epithelial cells to adenoviral infection. Am J Respir Cell Mol Biol 23:610-617.

McLachlan RI, Wreford NG, Meachem SJ, Kretser DMD, Robertson DM. 1994 Effets of testosterone on spermatogenic cell populations in the adult rat. Bio Repord 51:945-955.

McLachlan RI, O'Donnell L, Meachem SJ, Stanton PG, de Kretser DM, Pratis K, Robertson DM. 2002a. Identification of specific sites of hormonal regulation in spermatogenesis in rats, monkeys, and man. Recent Prog Horm Res 57:149179

McLachlan RI, O’Donnell L, Meachem SJ, Stanton PG, Kretser DMD, Pratis k, Robertson DM. 2002b. Hormonal regulation of spermatogenesis in primate and man: Insights for development of the male hormonal contraceptive. Androl 23:149-162.

Mruk DD, Cheng CY. 2004a. Sertoli-Sertoli and Sertoli-germ cell interactions and their significance in germ cell movement in the seminiferous epithelium during spermatogenesis. Endocr Rev 25:747-806.

Mruk DD, Cheng CY. 2004b. Cell-cell interactions at the ectoplasmic specialization in the testis. Trends Endocrinol Metab 15:439-447.

Noe G, Suvisaari J, Martin C, Moo-Young A, Sundaram K, Saleh SI, Quintero E Croxatto HB, Lahteenmaki P. 1999. Gonadotropin and testosterone suppression by 7a-methyl-19-nortestosterone acetate administered by subdermal implant to healthy men. Human Reprod 14:2200-2206.

O'Donnell L, McLachlan RI, Wreford NG, de Kretser DM, Robertson DM. 1996. Testosterone withdrawal promotes stage-specific detachment of round spermatids from the rat seminiferous epithelium. Biol Reprod 55:895-901.

O'Donnell L, Stanton PG, Bartles JR, Robertson DM. 2000. Sertoli cell ectoplasmic specializations in the seminiferous epithelium of the testosterone-suppressed adult rat. Biol Reprod 63:99-108

Perez-Moreno M, Jamora C, Fuchs E. 2003. Sticky business: Orchestrating cellular signals at adherens junctions. Cell 112:535-548.

Robaire B, Ewing LL, Irby DC, Desjardins C. 1979. Interactions of testosterone and estradiol-17b on the reproductive tract of the male rat. Biol Reprod 21:455463.

Rothen-Rutishauser B, Riesen FK, Braun A, Gunthert M, Wunderli-Allenspach H. 2002. Dynamics of tight and adherens junctions under EGTA treatment. J Membrane Biol 188:151-162.

Russell LD. 1977. Movement of spermatocytes from the basal to the adluminal compartment of the rat testis. Am J Anat 148:313-328.

Russell LD, Peterson RN. 1985. Sertoli cell junctions: Morphological and functional correlates. Int Rev Cytol 94:177-211.

Sakisaka T, Takai Y. 2004. Biology and pathology of nectins and nectin-like molecules. Curr Opin Cell Biol 16:513-521.

Siu MKY, Cheng CY. 2004a. Dynamic cross-talk between cells and the extracellular matrix in the testis. BioEssays 26:978-992.

Siu MKY, Cheng CY. 2004b. Extracellular matrix: Recent advances on its role in junction dynamics in the seminiferous epithelium during spermatogenesis. Biol Reprod $\underline{X X}^{\mathrm{Q} 6}: 375-391$ 
Siu MKY, Cheng CY. 2004c. Interactions of proteases, protease inhibitors, and the b1 integrin/laminin g3 protein complex in the regulation of ectoplasmic specialization dynamics in the rat testis. Biol Reprod 70:945-964.

Siu MKY, Lee WM, Cheng CY. 2003a. The interplay of collagen IV, tumor necrosis factor-a, gelatinase B (matrix metalloprotease-9), and tissue inhibitor of metalloproteases-1 in the basal lamina regulates Sertoli cell-tight junction dynamics in the rat testis. Endocrinology 144:371-387.

Siu MKY, Mruk DD, Lee WM, Cheng CY. 2003b. Adhering junction dynamics in the testis are regulated by an interplay of b1-integrin and the focal adhesion complex-associated proteins. Endocrinology 144:2141-2163.

Takai Y, Nakanishi H. 2003. Nectin and afadin: Novel organizers of intercellular junctions. J Cell Sci 116:17-27.

Toyama Y, Maekawa M, Yuasa S. 2003. Ectoplasmic specializations in the Sertoli cell: News vistas based on genetic defects and testicular toxicology. Anat Sci Int $78: 1-16$.

Troxell ML, Chen YT, Cobb N, Nelson WJ, Marrs JA. 1999. Cadherin function in junctional complex rearrangement and posttranslational control of cadherin expression. Am J Physiol Cell Physiol 276:C404-C418.

Venkiteswaran K, Xiao K, Summers S, Calkins CC, Vincent PA, Pumiglia K, Kowalczyk AP. 2002. Regulation of endothelial barrier function and growth by
VE-cadherin, plakoglobin, and beta-catenin. Am J Physiol Cell Physiol 283:C811-C821.

Vogl AW, Pfeiffer DC, Mulholland D, Kimel G, Guttman J. 2000. Unique and multifunctional adhesion junctions in the testis: Ectoplasmic specializations. Arch Histol Cytol 63:1-15.

von Eckardstein S, Noe G, Brache V, Nieschlag E, Croxatto H, Alvarez F, MooYoung A, Sivin I, Kumar N, Small M, Sundaram K. 2003. A clinical trial of 7amethyl-19-nortestosterone implants for possible use as a long-acting contraceptive for men. J Clin Endocrinol Metab 88:5232-5239.

Wine RN, Chapin RE. 1999. Adhesion and signaling proteins spatiotemporally associated with spermiation in the rat. J Androl 20:198-213.

Wong CH, Mruk DD, Lui WY, Cheng CY. 2004. Regulation of blood-testis barrier dynamics: An in vivo study. J Cell Sci 117:783-798.

Wu J, Gregory C, DePhilip R. 1993. Expression of E-cadherin in immature rat and mouse testis and in rat Sertoli cell cultures. Biol Reprod 49:13531361.

Xia W, Cheng CY. 2005. TGF-b3 regulates anchoring junction dynamics in the seminiferous epithelium of the rat testis via the Ras/ERK signaling pathway: An in vivo study. Dev Biol ( $\underline{\operatorname{In}}^{\mathrm{Q7}}$ Press).

Q1: Please check the suitability of short title.

Q2: Please check the change made in the year, is it ok?

Q3: Please provide complete location.

Q4: Reference is not cited in the reference list, please check.

Q5: Please check the change made, is it ok?

Q6: Please provide volume number.

Q7: Please update the information.

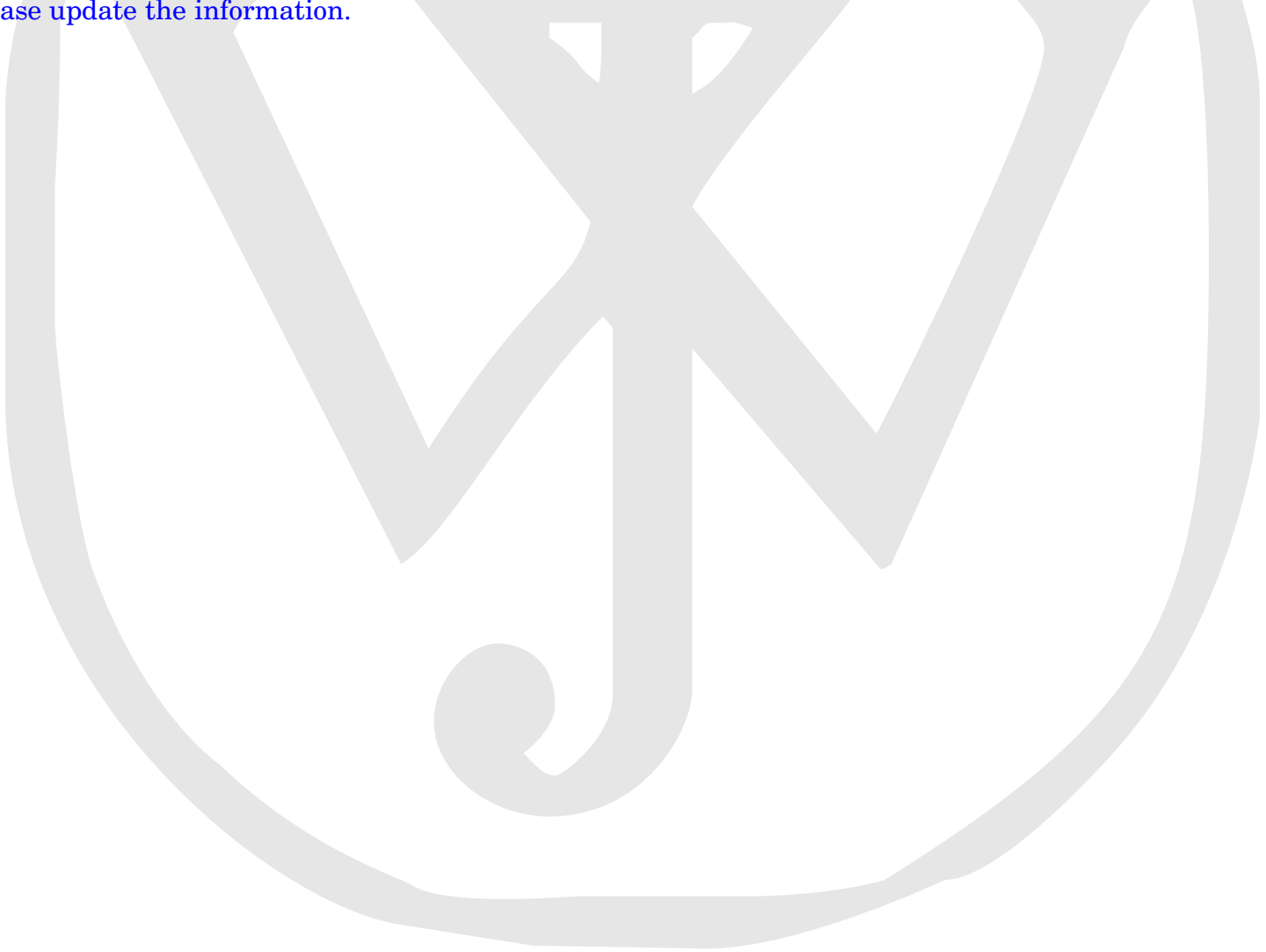




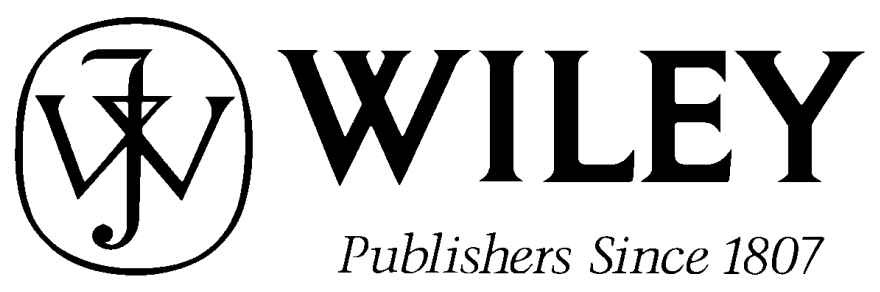

\author{
111 River Street, Hoboken, NJ 07030 \\ electronic proof checklist, Journal of Cellular Physiology

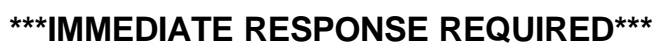 \\ Please follow these instructions to avoid delay of publication.
}

\title{
READ PROOFS CAREFULLY
}

- This will be your only chance to review these proofs.

- Please note that the volume and page numbers shown on the proofs are for position only.

ANSWER ALL QUERIES ON PROOFS (Queries for you to answer are attached as the last page of your proof.)

- Mark all corrections directly on the proofs. Note that excessive author alterations may ultimately result in delay of publication and extra costs may be charged to you.

CHECK FIGURES AND TABLES CAREFULLY (Color figures will be sent under separate cover.)

- Check size, numbering, and orientation of figures.

- All images in the PDF are downsampled (reduced to lower resolution and file size) to facilitate Internet delivery. These images will appear at higher resolution and sharpness in the printed article.

- Review figure legends to ensure that they are complete.

- Check all tables. Review layout, title, and footnotes.

\section{COMPLETE REPRINT ORDER FORM}

- Fill out the attached reprint order form. It is important to return the form even if you are not ordering reprints. You may, if you wish, pay for the reprints with a credit card. Reprints will be mailed only after your article appears in print. This is the most opportune time to order reprints. If you wait until after your article comes off press, the reprints will be considerably more expensive.

RETURN

$\square$ PROOFS

REPRINT ORDER FORM

$\square$ CTA (If you have not already signed one)

RETURN WITHIN 48 HOURS OF RECEIPT VIA FAX TO MATT HOLLENDER AT 201-748-6052

QUESTIONS?
Matt Hollender, Associate Production Editor

Phone: $201-748-5910$

E-mail:mhollend@wiley.com

Refer to journal acronym and article production number

(i.e., JCP 00-001 for Journal of Cellular Physiology ms 00-001). 
Date:

To:
Production/Contribution

ID\#

Publisher/Editorial office use only

Re: Manuscript entitled

(the "Contribution") (the "Journal")

for publication in JOURNAL OF CELLULAR PHYSIOLOGY

published by Wiley-Liss, Inc., a subsidiary of John Wiley \& Sons, Inc. ( "Wiley").

Dear Contributor(s):

Thank you for submitting your Contribution for publication. In order to expedite the publishing process and enable Wiley to disseminate your work to the fullest extent, we need to have this Copyright Transfer Agreement signed and returned to us as soon as possible. If the Contribution is not accepted for publication this Agreement shall be null and void.

\section{A. COPYRIGHT}

1. The Contributor assigns to Wiley, during the full term of copyright and any extensions or renewals of that term, all copyright in and to the Contribution, including but not limited to the right to publish, republish, transmit, sell, distribute and otherwise use the Contribution and the material contained therein in electronic and print editions of the Journal and in derivative works throughout the world, in all languages and in all media of expression now known or later developed, and to license or permit others to do so.

2. Reproduction, posting, transmission or other distribution or use of the Contribution or any material contained therein, in any medium as permitted hereunder, requires a citation to the Journal and an appropriate credit to Wiley as Publisher, suitable in form and content as follows: (Title of Article, Author, Journal Title and Volume/Issue Copyright (C) [year] Wiley-Liss, Inc. or copyright owner as specified in the Journal.)

\section{B. RETAINED RIGHTS}

Notwithstanding the above, the Contributor or, if applicable, the Contributor's Employer, retains all proprietary rights other than copyright, such as patent rights, in any process, procedure or article of manufacture described in the Contribution, and the right to make oral presentations of material from the Contribution.

\section{OTHER RIGHTS OF CONTRIBUTOR}

Wiley grants back to the Contributor the following:

1. The right to share with colleagues print or electronic "preprints" of the unpublished Contribution, in form and content as accepted by Wiley for publication in the Journal. Such preprints may be posted as electronic files on the Contributor's own website for personal or professional use, or on the Contributor's internal university or corporate networks/intranet, or secure external website at the Contributor's institution, but not for commercial sale or for any systematic external distribution by a third party (e.g., a listserve or database connected to a public access server). Prior to publication, the Contributor must include the following notice on the preprint: "This is a preprint of an article accepted for publication in [Journal title] @ copyright (year) (copyright owner as specified in the Journal)". After publication of the Contribution by Wiley, the preprint notice should be amended to read as follows: "This is a preprint of an article published in [include the complete citation information for the final version of the Contribution as published in the print edition of the Journal]", and should provide an electronic link to the Journal's WWW site, located at the following Wiley URL: http://www.interscience.Wiley.com/. The Contributor agrees not to update the preprint or replace it with the published version of the Contribution. 
2. The right, without charge, to photocopy or to transmit online or to download, print out and distribute to a colleague a copy of the published Contribution in whole or in part, for the Contributor's personal or professional use, for the advancement of scholarly or scientific research or study, or for corporate informational purposes in accordance with Paragraph D.2 below.

3. The right to republish, without charge, in print format, all or part of the material from the published Contribution in a book written or edited by the Contributor.

4. The right to use selected figures and tables, and selected text (up to 250 words, exclusive of the abstract) from the Contribution, for the Contributor's own teaching purposes, or for incorporation within another work by the Contributor that is made part of an edited work published (in print or electronic format) by a third party, or for presentation in electronic format on an internal computer network or external website of the Contributor or the Contributor's employer.

5. The right to include the Contribution in a compilation for classroom use (course packs) to be distributed to students at the Contributor's institution free of charge or to be stored in electronic format in datarooms for access by students at the Contributor's institution as part of their course work (sometimes called "electronic reserve rooms") and for inhouse training programs at the Contributor's employer.

\section{CONTRIBUTIONS OWNED BY EMPLOYER}

1. If the Contribution was written by the Contributor in the course of the Contributor's employment (as a "work-madefor-hire" in the course of employment), the Contribution is owned by the company/employer which must sign this Agreement (in addition to the Contributor's signature), in the space provided below. In such case, the company/employer hereby assigns to Wiley, during the full term of copyright, all copyright in and to the Contribution for the full term of copyright throughout the world as specified in paragraph A above.

2. In addition to the rights specified as retained in paragraph $B$ above and the rights granted back to the Contributor pursuant to paragraph $\mathrm{C}$ above, Wiley hereby grants back, without charge, to such company/employer, its subsidiaries and divisions, the right to make copies of and distribute the published Contribution internally in print format or electronically on the Company's internal network. Upon payment of the Publisher's reprint fee, the institution may distribute (but not resell) print copies of the published Contribution externally. Although copies so made shall not be available for individual re-sale, they may be included by the company/employer as part of an information package included with software or other products offered for sale or license. Posting of the published Contribution by the institution on a public access website may only be done with Wiley's written permission, and payment of any applicable fee(s).

\section{E. GOVERNMENT CONTRACTS}

In the case of a Contribution prepared under U.S. Government contract or grant, the U.S. Government may reproduce, without charge, all or portions of the Contribution and may authorize others to do so, for official U.S. Government purposes only, if the U.S. Government contract or grant so requires. (U.S. Government Employees: see note at end).

\section{F. COPYRIGHT NOTICE}

The Contributor and the company/employer agree that any and all copies of the Contribution or any part thereof distributed or posted by them in print or electronic format as permitted herein will include the notice of copyright as stipulated in the Journal and a full citation to the Journal as published by Wiley.

\section{G. CONTRIBUTOR'S REPRESENTATIONS}

The Contributor represents that the Contribution is the Contributor's original work. If the Contribution was prepared jointly, the Contributor agrees to inform the co-Contributors of the terms of this Agreement and to obtain their signature to this Agreement or their written permission to sign on their behalf. The Contribution is submitted only to this Journal and has not been published before, except for "preprints" as permitted above. (If excerpts from copyrighted works owned by third parties are included, the Contributor will obtain written permission from the copyright owners for all uses as set forth in Wiley's permissions form or in the Journal's Instructions for Contributors, and show credit to the sources in the Contribution.) The Contributor also warrants that the Contribution contains no libelous or unlawful statements, does not infringe on the rights or privacy of others, or contain material or instructions that might cause harm or injury. 


\section{CHECK ONE:}

[__ C Contributor-owned work

Contributor's signature $\quad$ Date

Type or print name and title

Co-contributor's signature

Date

Type or print name and title

ATTACH ADDITIONAL SIGNATURE PAGE AS NECESSARY

]Company/Institution-owned work (made-for-hire in the

Company or Institution (Employer-for-Hire)

Date

course of employment)

Authorized signature of Employer

Date

\section{[__ ] U.S. Government work}

\section{Note to U.S. Government Employees}

A Contribution prepared by a U.S. federal government employee as part of the employee's official duties, or which is an official U.S. Government publication is called a "U.S. Government work," and is in the public domain in the United States. In such case, the employee may cross out Paragraph A.1 but must sign and return this Agreement. If the Contribution was not prepared as part of the employee's duties or is not an official U.S. Government publication, it is not a U.S. Government work.

\section{[__ ] U.K. Government work (Crown Copyright)}

\section{Note to U.K. Government Employees}

The rights in a Contribution prepared by an employee of a U.K. government department, agency or other Crown body as part of his/her official duties, or which is an official government publication, belong to the Crown. In such case, the Publisher will forward the relevant form to the Employee for signature. 


\section{(W) WILEY \\ Journal of Cellular Physiology}

Telephone Number.

- Facsimile Number.

To: Mr. Matt Hollender

Fax: 201-748-6052

From:

Date:

Re: Journal of Cellular Physiology, ms \# 
C1

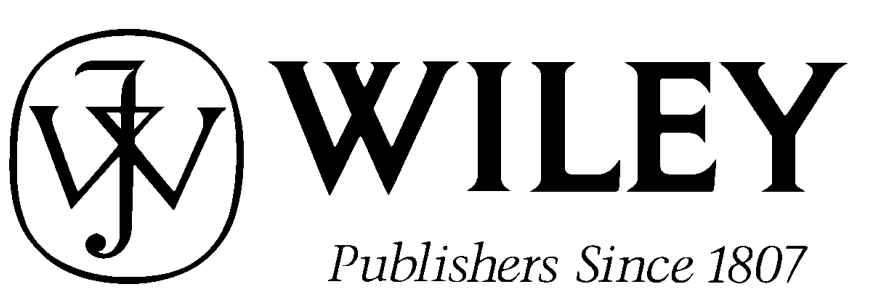

\section{REPRINT BILLING DEPARTMENT • 111 RIVER STREET ・ HOBOKEN, NJ 07030 \\ PHONE: (201) 748-6353; FAX: (201) 748-6052 \\ E-MAIL: reprints@wiley.com \\ PREPUBLICATION REPRINT ORDER FORM}

Please complete this form even if you are not ordering reprints. This form MUST be returned with your corrected proofs and original manuscript. Your reprints will be shipped approximately 4 weeks after publication. Reprints ordered after printing will be substantially more expensive.

JOURNAL JOURNAL OF CELLULAR PHYSIOLOGY

VOLUME

ISSUE TITLE OF MANUSCRIPT MS. NO. NO. OF PAGES AUTHOR(S)

\begin{tabular}{|c|c|c|c|c|c|}
\hline No. of Pages & 100 Reprints & 200 Reprints & 300 Reprints & 400 Reprints & 500 Reprints \\
\hline & $\$$ & $\$$ & $\$$ & $\$$ & $\$$ \\
\hline $1-4$ & 336 & 501 & 694 & 890 & 1052 \\
\hline $5-8$ & 469 & 703 & 987 & 1251 & 1477 \\
\hline $9-12$ & 594 & 923 & 1234 & 1565 & 1850 \\
\hline $13-16$ & 714 & 1156 & 1527 & 1901 & 2273 \\
\hline $17-20$ & 794 & 1340 & 1775 & 2212 & 2648 \\
\hline $21-24$ & 911 & 1529 & 2031 & 2536 & 3037 \\
\hline $25-28$ & 1004 & 1707 & 2267 & 2828 & 3388 \\
\hline $29-32$ & 1108 & 1894 & 2515 & 3135 & 3755 \\
\hline $33-36$ & 1219 & 2092 & 2773 & 3456 & 4143 \\
\hline $37-40$ & 1329 & 2290 & 3033 & 3776 & 4528 \\
\hline
\end{tabular}

Please send me

Please add appropriate State and Local Tax

for United States orders only.

\section{$* *$ International o
Please check one:}

If credit card order, charge to:

Credit Card No

BILL TO:

Name

Institution

Address

Purchase Order No. reprints of the above article at

(Tax Exempt

No.

Please add 5\% Postage and Handling

TOTAL AMOUNT OF ORDER**

ust be paid in currency and drawn on a U.S. bank

$\square$ Check enclosed $\square$ Bill me

$\square$ American Express $\square$ Visa Signature

Exp. Date

$\$$

$$
\$
$$

Credit Card

MasterCard

Phone

Fax

E-mail 


\section{Softproofing for advanced Adobe Acrobat Users - NOTES tool}

NOTE: ACROBAT READER FROM THE INTERNET DOES NOT CONTAIN THE NOTES TOOL USED IN THIS PROCEDURE.

Acrobat annotation tools can be very useful for indicating changes to the PDF proof of your article. By using Acrobat annotation tools, a full digital pathway can be maintained for your page proofs.

The NOTES annotation tool can be used with either Adobe Acrobat 3.0x or Adobe Acrobat 4.0. Other annotation tools are also available in Acrobat 4.0, but this instruction sheet will concentrate on how to use the NOTES tool. Acrobat Reader, the free Internet download software from Adobe, DOES NOT contain the NOTES tool. In order to softproof using the NOTES tool you must have the full software suite Adobe Acrobat Exchange 3.0x or Adobe Acrobat 4.0 installed on your computer.

\section{Steps for Softproofing using Adobe Ac robat NOTES tool:}

1. Open the PDF page proof of your article using either Adobe Acrobat Exchange 3.0x or Adobe Acrobat 4.0. Proof your article on-screen or print a copy for markup of changes.

2. Go to File/Preferences/Annotations (in Acrobat 4.0) or File/Preferences/Notes (in Acrobat 3.0) and enter your name into the "default user" or "author" field. Also, set the font size at 9 or 10 point.

3. When you have decided on the corrections to your article, select the NOTES tool from the Acrobat toolbox and click in the margin next to the text to be changed.

4. Enter your corrections into the NOTES text box window. Be sure to clearly indicate where the correction is to be placed and what text it will effect. If necessary to avoid confusion, you can use your TEXT SELECTION tool to copy the text to be corrected and paste it into the NOTES text box window. At this point, you can type the corrections directly into the NOTES text box window. DO NOTcorrect the text by typing directly on the PDF page.

5. Go through your entire article using the NOTES tool as described in Step 4.

6. When you have completed the corrections to your article, go to File/Export/Annotations (in Acrobat 4.0) or File/Export/Notes (in Acrobat 3.0). Save your NOTES file to a place on your harddrive where you can easily locate it. Name your NOTES file with the article number assigned to your article in the original softproofing e-mail message.

\section{When closing your artic le PDF be sure NOT to save changes to original file.}

8. To make changes to a NOTES file you have exported, simply re-open the original PDF proof file, go to File/Import/Notes and import the NOTES file you saved. Make changes and reexport NOTES file keeping the same file name.

9. When complete, attach your NOTES file to a reply e-mail message. Be sure to include your name, the date, and the title of the journal your article will be printed in. 